

$$
\text { . }
$$$$
\text { .' }
$$ 




\title{
SOME APPLICATIONS
}

OF

\section{Logical and Psychological Principles}

\author{
TO GRAMMAR.
}

Presented to The Faculty of The

UNIVERSITY OF MinNesota

AS

\section{A $\mathbb{1}$ hrtits,}

For the Degree of Doctor of PhILosophy,

BY

PETER MAGNUS MAGNUSSON, A. B.

1893.

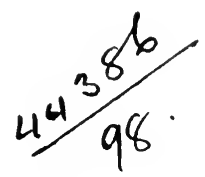


Digitized by the Internet Archive in 2007 


\section{TABLE OF CONTENTS.}

\section{PART I.}

I. The World of Presentations.

Introductory. The Presentation-world as distinguished from the conceptual world. The unity of the presentation world.

II. Symbol and Thought.

Objectification. Meaning and symbol are inseparable, still meaning is not symbol. May not meaning, as the concept, be a part of the symbol?

III. Language, Symbol, and Reality.

Symbolism and language. Artificial symbols. Practical value of this distinction. Meaning and reality. The real and ideal in the conceptual world.

\section{PART II.}

The Statics of the Symbolism of Thought.

IV. The Fundamental Thought-forms.

Contrast between the contents of time and space. The result of this contrast in science.

V. The Categories of Space.

The category of thing. Number. The category of quality. The category of position. Review. Summary.

VI. The Categories of Time.

The category of event. The double thought-form of an event. Duration. The category of variation or manner 
Chapter.

VII. The Categories of Time (continued).

The category of succession. State. State compared with case. Succession as represented by conjunctions. Summaries of categories of time.

VIII. The Categories in General.

Abstraction. Change of category. Comparison of categories. Summary

PART III.

The Dynamics of the Symbolism of Thought and The Elements of Syntax.

IX. Assertion.

Introductory. Assertion. The ideal and the real in relation to assertion. Definition of assertion. How expressed. Modes. Times.

X. Predication.

Construction. What is asserted? Subject and predicate. Definition of predication. The subject included in the verb. The subject. The predicate. The "copula." The union of subject and predicate. Contrast of predication and assertion. Voice.

XI. Determination (or "modification").

Division of determination. Internal determination by words. Attribution. Modification. Identitive determination. Apposition. By predicative.

XII. Determination (continued) Objects.

External determination, or location. Thing-determining objects. Motion-determining objects. The accusative object. The dative objects. Circumstantial objects. Prepositions and objects

XIII. Determination (concluded).

Determination by propositions. Propositions determining words. Propositions determining propositions. (1) Mutual determination; (2) determination by subordinate propositions. Double symbolism. Outline of syntax 
PART IV.

Morphology, or the Parts of Speech.

CHAPTER.

XIV. Prolegomena to Morphology.

What is a word? The existence of a word-form. To know, and to know that we know. The center of interest. Teleological economy.

$\mathrm{XV}$. Words belonging to the Categories of Space.

Substantives. Nouns and pronouns. Adjectives. Expression for space-relations. Prepositions in modern languages. Analysis of the substantive. Classification of words belonging to the space-presentations.............

XVI. Words belonging to the Categories of Time.

Verbs. Classes. Properties. Predication-power. Assertion. Adverbs. Conjunctions. Inflection of English verb. Classification of Latin tenses. Of French tenses. Of English and German tenses. Analysis of the English verb. Classification of words belonging to time presentations.

XVII. Words belonging both to the Categories of Space and the Categories of Time.

The characteristics of participials. Substantive participials. Adjective participials. Classification. Analysis of participials. List of classes of words, or "parts of speech"

PART V.

Syntax.

XVIII. Analysis of Verbal Phrases.

The syntax of the primary symbols of events. Kinds of primary event-symbols in English. In Spanish. The secondary symbols.

PART VI.

Application.

XIX. A System of Diagrams.

XX. Analysis of Disputed Constructions.

The "passive voice." The "perfect tenses." "The 
Chapter.

PAGE.

"future tenses," and the "potential mode." Some

German "compound verbs." Latin. Modern Greek... 113

PART VII.

Conclusion.

XXI. Summary. 


\section{Prefatory Note.}

This thesis should be read in the same manner as an impatient novel-reader peruses fiction. The last chapter ought to be read both first and last. Economy of space alone forbids us to print it twice. After reading the summary, those philologically inclined will find more of interest to themselves in the latter half of the thesis.

The tabulated "analyses" and "summaries", found generally at the end of the chapters, will give a comprehensive conception of the system, and are hence the most important parts of the text. 



\title{
PARTI.
}

\author{
Symbol And MeAning.
}

\section{CHAPTER I.}

The World of P'resentations.

Introductory.-The fate of grammar has been a peculiar one, for it is at once one of the most advanced and favored sciences, and one of the most neglected and chaotic. To this result several causes co-operate, of which the following, perhaps, are the most important. The modern tendency is to make all research historical research, and to reduce all knowledge to history. Were it not such a worn out commonplace, we should have said: All modern study is study of evolution. But the very fact that this is a commonplace in all science shows how it overshadows modern thought. Philology has proved a most fruitful field for historical study, and the enthusiasm of the student has proved equal to the magnitude of his task. The history of the phonetic elements of language has been traced back for centuries with an acuteness and patience that is astonishing. The physiological production and evolution of articulate sounds has been closely investigated. The history of every ending in declensions and conjugations has been carefully unfolded, and we are informed of the historical route by which complex constructions have come from simpler. But the 
very success of the historical method has blinded men to its limitations, and they have forgotten that showing how a thing arose does not decide what it is. The history of a development is not its philosophy. The order in which phenomena have arisen does not give the rational ground of any one phenomenon in the succession. By its very nature it is descriptive. This is overlooked, so that the same scientist who would look with pharisaical horror at a little historical inexactness, complacently uses a terminology in syntax and inflection that implies the gravest contradictions in his philosophy of the sentence. He speaks of an English passive voice, confounds predication and assertion, and even classes auxiliaries among connectives. Another source of this neglect of the philosophical principles of grammar lies in the modern tendency to make all science natural science, and to consider natural equivalent to physical. Hence, philology has come to mean chiefly phonetics with as close alliance as possible to the physiology of the speech organs. Take as an example Cook's Siever's Old English Grammar. This excellent and standard work has almost no syntax and nothing but the traditional tables of conjugations and declensions in addition to its very voluminous historical phonetics. Still it is called a grammar; and this is a typical example of the most modern work in that science.

Of late a more philosophical tendency has made itself manifest in the field of philology. But even in such books as Sweet's "New English Grammar," and Paul's "Principles of Language," the purely philosophical portion is treated as if of secondary importance; and hence the old saws of the Schoolmen and the assumptions of modern scientists are unsystematically jumbled together and uncritically accepted as the very starting-points and foundations of the science; $\checkmark$ and so it is still true that logic and psychology are neglected for history, physics and physiology in the study of grammar. Our present purpose is to do what we can in this neglected field of inquiry.

Before we enter upon our task, it may be well to preface the discussion in this chapter by an explanation. As this chapter is to lay the foundation, it is necessary to treat of 
some conceptions of psychology, and the writer has constantly been in doubt as to what should be stated and what left to be understood. Even where there is practically no dispute among modern psychologists, it seemed sometimes necessary for the sake of symmetry to mention and develop the principle-naturally in the shortest manner possible. Secondly, it happens that no two psychologists agree as to what are the settled principles of modern psychology. In the main any two generally agree on the list of settled principles with but one or two pet provisos; but the sum of all pet heresies forms probably just as large and just as fundamental a body of principles as the catholic canon of the science. Hence when doubtful whether a doctrine germane to the discussion is generally accepted or not, we have taken the benefit of the doubt and have briefly explained our position.

The presentation-world as distinguished from the conceptual world.-Consciousness can be dichotomized into a presentation-world and a world of meaning. Equivalent divisions of the contents of consciousness are too well known to need mention here. The Kantian sense-world is an example of the first. But as few philosophical distinctions have been more seriously misunderstood than this division of the known world into a sense-world on the one hand and an intelligible world, or a world of meaning, on the other, it may be well to pause a moment over the difference between them.

The object of knowledge may be divided into folt worldr and understood world, or presentation-world and world of meaning. These divisions are equivalent.

The presentation-world is the object of knowledge as it is presented to us; that is, as it is "unconsciously" or rather involuntarily construed by the perceptive faculty. It consists of perceptions qua perceptions. It is that which is heard, seen, felt, imagined, and remembered, just as it is heard, seen, felt, imagined, and remembered, without any additional content derived from voluntary or explicit ("conscious") reflection on these phenomena. A few illustrations will perhaps "force the reader to understand" the 
distinction. If a straight stick is partly immersed at an oblique angle in water, we say it appears crooked but is straight. The crooked appearance belongs to the senseworld, the knowledge that it is still a straight stick belongs to the conceptual world. Now, if the stick is withdrawn from the water, it will appear as well as be a straight stick. We say now that the appearance is true; but we must not lose sight of the fact that the visual percept of the stick, whether straight or crooked, whether false or true, qua per-. cept, is still nothing but an appearance, and as such belongs to the presentation-world. The sun as an object in my presentation-world is about as large as a dinner plate. As a presentation it is no larger than it appears; for an appearance as an appearance, can be nothing but what it appears to be. This is a truism almost too trivial to repeat. However, it is certain that after taking into account the whole of my own and parts of other men's experience, I must interpret the bright, circular disk in the sky to mean an immense spherical body a million times the size of the earth. This is, however, conceptual knowledge, not sense (or presentation) knowledge at all; for I can neither see nor imagine a body a million times larger than the earth, if we consider size as something absolute. In the conceptual world parallel lines never meet, in the presentation-world they do meet at the horizon. Space as conceived is infinite, space as perceived is limited on all sides; when not by an opaque body, by the vault of the sky. The very concept of time denies that time has beginning or end*, but time as "perceived," imagined in the future, or remembered in the past, is limited both exparte ante et ex parte post. As an example, take the "third dimension" of space. Many harbor a lurking or open suspicion that we do not possess this dimension by the same warranty deed as the other two. For do we not construct this dimension, and that from spatial data of only two dimensions? This confusion comes from not making a distinction between the "conscious" and "uncon-

*Dr. W. T. Harris' vindication of the truth of the infinity of time and space, as against the Hamiltonian theory of the conditioned, seems to us conclusive. Hence we state without further argument that time and space as conceived are infinite, and refer possible objectors to. Mr. Harris. 
scious" constructions of the mind, the "judgment," if it may so be called, by which a percept is construed, and the explicit judgment. All perception is construction. The perceiving mind arranges and interprets that which is given in sensation into a sense-cosmos, and only as it is thus arranged are we conscious of the sense-world. But this arranging and interpreting is done implicitly and involuntarily, and it appears to us as if the sense-world, or, more exactly, the presentation-world, were given to us just as it exists, a cosmos in time and space. Not only the third dimension in sightperception, but the other two dimensions also, as well as the percepts of the other senses and the images of imagination, are in the same sense construed by what we call apperception. Apperceptive inference is therefore included in the presentation-world, while explicit interpretation belongs to the conceptual world. Our perceptions of the third dimension are imperfect, but not wanting. A foot's distance at right angles to the horizon on the plane of the horizon seems shorter the farther it is from the eye, but still it seems of some length. We do not judge simply, we see the distance.

For our present purpose the interest in the dichotomy of the contents of consciousness into sense and understanding, presentation-world and concept-world, centres almost exclusively in the former of these divisions. This may be summed up thus:

The presentation-world is the world of appearances; it is the content of our consciousness so far as presented to us by the activities of our senses and the imagination. The presentation-world is not the sensations merely, for they form no world (no unified experience) as mere sensations; but it is the cosmos of perception. Hence it does not exclude the "unconscious inferences" implied in apperception. All explicit judgment about the objects of this world is consequently excluded. The thesis of the present section can be held alike by realist and idealist. No sane man believes that a stick necessarily is bent when it appears so.

The unity of the presentation-world.-Prescutation is here used as a common name for percepts and images, in short, for all that appears to us under the forms of time and 
space. Hence the presentation-world includes, first of all, the sense-world in the stricter sense. All that is perceived by the "five senses," the temperature sense, muscular sense, and "organic" senses, is, considered as percept simply, presentation. The images by which memory recalls the past, and the images voluntarily constructed by the imagination, and without our will by the phantasy in reverie or dreams, are also here classed as presentations. In this paragraph we shall attempt to show that there is no intrinsic difference between images and percepts; also, that all presentations are members of one world whose bonds of union are time and space:

First, the tactual and visual worlds coincide; we have the same time and space in touch as in vision. The object felt under the table is located in the same space-continuum as the object seen above it. This is probably admitted by all.

Hearing is sometimes asserted to be a time-sense, but not a space-sense. This may be true, with some qualifications. A being without sight and touch and with only one ear might perhaps have absolutely no space perception. His consciousness would have the time-form only, and it is altogether impossible for us to imagine his world; but for one who possesses either touch or sight, sounds are located spontaneously, and as far as we can know, from the beginning. Sound not only appears to come from a certain direction, but also from a more or less definite distance. Nor is it necessary to bring in any explicit judgment to locate sounds, for they appear by apperception, far or near, east or west. Sense, not understanding, locates sound where it appears to be. This can be plainly shown to be the case when sense and understanding disagree. The sound of the church-bells seems to come directly from the south because the open window of the room is in that direction from the listener, and the sound may continue to appear to come from the south even if the listener knows that the bells are to the east of him. If sound were incapable of the spaceform, not only should we not continually locate it, but it would be impossible ever to locate it. 
Taste and smell have been called subjective senses void of spatial perception. If the question were whether a being with only taste and smell could develop his space perception, it might be true; but with this question we have nothing to do. Tastes and smells, however, perceived by persons that have also the sense of touch are always located in the nose and mouth. Nobody ever located the taste of sugar or the odor of violets in his finger.

The same line of reasoning can be applied to the temperature sense, the muscular sense, and the senses of organic condition. These senses may be more or less vague, but so much at least is certain, that they indubitably refer the feeling to some space object, if not more definitely, to our whole body. We are in no doubt when hungry as to whose stomach is in need, or when sea-sick as to whose head and general system is in unstable equilibrium. Therefore we can safely conclude that the world of sense-perception is one, spatial, and finite.

But to the world of sense-perception should be added the world of memory and imagination. As a common name for the products, or contents, of memory and imagination we shall use the term images. As to the condition of their production, images are, and sense-percepts are not, independent of outer sense organs; but as presentations, images differ from sense-percepts only in degree and not always in that.* It may be objected, that in such a case we might mistake images for percepts. The answer is: We often do. Who has not sometimes when listening to the dying strains of an organ, been in doubt as to when the organ stopped and imagination began? The pioneer's boy knows by sad experience how hard it is to tell whether he hears or imagines he hears the cow-bell in the forest. Many a ghost story is a testimony to the ease with which an image plays the rôle of a visual percept. This theory, however, is fraught with what seems at first awful consequences. It forces us to believe that an imagination "idea" of red is a red "idea", and that an imagination idea of extension is an

\footnotetext{
*See against this view "Lotze's Outlines of Psychology, translated by Ladd, p. 33 , also p. 28 .
} 
extended idea.* First, however, we must know that properly speaking we can not be said to have either images or percepts of mere extension or mere color. The nearest we can come to this is to have an image or percept of an extended or a colored thing. But the image is as extended and colored as the percept. Plainly, the imagining subject need not be extended and colored any more than the subject as perceiving is, and the act of imagination any more than the act of perception. But the important thing to hold fast for our present purpose is the fact that the redness of a color, the pitch of a sound, and the dimensions of a figure are of the same nature in the image as in the percept. There are not two blue colors, one imagined and one perceived. Every night that we dream, this is proved true. Do we not in dreams walk about in what we take for broad daylight among shapes that we take for percepts? The following experiment can be tried by anyone: After retiring, when the mind is no longer busy with active interests, close tle eyes and concentrate the attention on one of the floating shapes of imagination that then troop past the mind. Soon it will be hard to distinguish this product of the imagination from the floating coruscations of light always seen in the fundus of the eye; and with more persistent attention, the similarity to a perception will be so startling as almost to suggest something uncanny. Goethe's seeing a flower grow out of a flower, and the painter's remembering his model perceptually are extreme examples in point; but there are none among us that have not often in sleep, and not seldom during their waking hours been betrayed into taking an image for a percept. The image crosses the boundary to the percept simply because there is no boundary to cross; $\checkmark$ for, while the production (process) of imagination is radically different from that of perception, one being bound to outer sense organs, the other not, one being partly voluntary, the other practically not, the products (results) differ, if at all, only in the degree of vividness. The images are referred to the same space as the percepts. The European immigrant

\footnotetext{
*In these sentences for the first and last time, we use the word "idea" in the sense of images of imagination and memory, a sense that never should be given to the word, but which still is imposed upon it even by careful writers.
} 
to America, when he lets his fancy reconstruct the scenes of his childhood, always locates them in the east; if on a journey we awaken in the night and think of our home, and then suddenly remember that we are in quite another direction from home than at first we supposed, we find that the whole scenery of imagination veers around so as to tally with geography. If imagined space were one affair and perceived space another, it could not make any conceivable difference where the person of the imaginer were located. Imagination has not a stage of its own where distances and directions are wholly arbitrary and independent of perceived space. It is well known to every psychologist that percep- tion and imagination can in no wise be separated. In what we name a percept, we generally imagine more than we see, hear, or feel, as the whole subject of apperception teaches. Of a friend's face, a page of reading in a familiar language, and of any other well known object, very little of what is perceived is seen, the greater part is an image gathered from hundreds of previous perceptions. If the images of recollection and imagination were of different nature or located in a different space-continuum than the percept, such co-operation as that which takes place in apperception would be impossible.

Our conclusion is therefore this: Images and percepts considered as presentations differ in degree only; are spatial, and all located in the same space-continuum. Thus there is but one space for the mind. That there is but one time for the mind may be taken for granted.

We have now attempted to show the unity and homogeneity of the presentation-world. This world is in timer and space, and in but one time and one space. Presentations qua presentations differ in nothing essential, whether they be images or percepts. Hence when, in the following pages, we lay down the laws of symbolism, we shall need to make no distinction between presentations. 


\section{CHAPTER II.}

\section{Symbol and Thought.}

Objectification.-The rational mind places the content of its consciousness ovet against itself as another to its Self, and thus its sensation becomes intuition, becomes an object of knowledge. Before the content of consciousness can be discriminated and synthesized into a world, it must be thus distinguished from the knower and still kept in relation to him; it must be objectified, placed over against the ego as that which is not the ego, but which still belongs to it. This is objectification. Hence it comes to pass that though consciousness knows itself primarily and immediately, yet as soon as the ego thinks an articulate thought, forms a judgment about itself, it must first make itself into its Other, think the ego as the non-ego; for before the subject becomes an object of thought, it can not be handled by our faculty of discursive reason. The procedure is similar when the object of thought is one of the past states of consciousness. To be an object of thought the state can not be thought of purely as a state of the subject, but as something not-me placed over against the subject. This truth has been disregarded by many psychologists, and as a consequence they have sooner or later awakened in wonder and amazement to the fact that the self has mysteriously but irretrievably been lost in their systems. They started out to philosophize with entire faith in the common-sense belief that the self, after all, is the most important thing about psychology, but after a "scientific investigation" they could find no self. Which is true enough; for to know scientifically we must objectify our knowledge, and hence in thus knowing the self we must first make it another than the subject, an object. This other into which all knowledge must be translated is, as a symbol, in time and space. Not that we may not know that certain realities of which we have knowledge transcend time and space, but only that we can not know these realities except in and through a space and time symbol. We still picture the soul as warm air, like the Stoics, or as a human 
figure with wings, like the Greek sculptors; and this in spite of the non-spatial doctrines we may hold about the conscious principle. Again, war is a grim soldier, a uniformed army, smoking cannon, devastated fields, or something else symbolic and pictorial, though the thinker knows full well that the abstract and collective noun in question means both more and less than any of these images. Thought is materialistic; its symbols move in time and space only. All joining of thought to thought, all movement, in one word, in the realm of thought, is done symbolically in a "materialistic" manner, by joining one presentation to another, and presentations, as we have seen, are spatial and temporal.

Meaning and symbol are inseparable and still meaning is not symbol.-The presentation-world as such is a symbol and a symbol only. "For logical purposes ideas are symbols and they are nothing but symbols", says F. H. Bradley*; but this is only one-half the truth. The other half is this: Meaning is found in symbols and in symbols only. An illustration may make our point clear. We say and think: the cause of the billiard ball's moving is the impact from the cue. How do we think this? What happens in our consciousness when we say we understand it? A ball and a cue are imagined, the ball at rest and the cue in motion; next the ball and the cue collide, and the ball begins to move. All this must be imagined; and conversely, this is all that can be imagined of the causal relation of the cue's motion to the ball's. All the presentation-world can deliver in the case is that the ball was at rest and began to move immediately upon contact with the cue; there is in this not the least germ of causality, for causality can not be seen. The presentation-world, as Hume abundantly proved, knows only succession where causality is affirmed. But though causality can not be pictured, no one can doubt that it exists as a concept. Hence it is plain that the meaning is not the symbol, and in this case at least, not even a part of the symbol. But if this is the case, why should not the philosophic mind, at least, think causality pure, that is,

"F. H. Bradley, The Principles of Logic, p. 3. "Idea" scems to be with Bradley, as with most other English writers, a word that has a number of meanings. Here it means presentation. 
without the picture gallery of imagination? Simply because it can not. This can be shown in many ways. We first become conscious of causality by perceiving some succession involving it ; never by "pure" thought. When we explain to another what is meant by causality, it is always by an example of cause and effect. Examples can, from the nature of the case, coine only from the presentation-world. Even the strictest definition involves a presentation symbol, and we can not "make it clear" to ourselves what we mean by the word without having recourse to an example from the presentation-world. Therefore: no meaning without symbol, but meaning is not symbol. This is the truth there is in the principle: Nihil est in intellectu quod non ante fuerit in sensu. Through sense and its equivalent, imagination, all the contents of the intellect are known; but, strictly speaking, the meaning always belonged to the intellect, and was never imported from the senses. Hence the Leibnitzian proviso, Nisi ipse intellectus, should be given its full force.

An example illustrating symbol and meaning may be of use. Let us ask how the astronomer thinks the solar system. What are the psychoses corresponding to words like the following? The diameter of the sun is ten times that of Jupiter. The diameter of Jupiter is ten times that of the earth. The orbit of Jupiter is an ellipse, lying outside of the earth's orbit, and a revolution in it is completed in twelve years. The astronomer and his listener, in order to understand these sentences, must imagine $(a)$ a fiery sphere of any convenient size for the sun, $(b)$ another partly glowing sphere of one-tenth the diameter of the former for Jupiter, $(c)$ a third sphere, for the earth, having the same relations and size to Jupiter as he has to the sun, $(d)$ these latter spheres must be set moving around the first. This would be the symbolism of the thought, and is a purely. space and time affair, consisting, as it does, of presentations only. But these symbols are never for a moment mistaken for the meaning by a rational and trained mind. This imagined fiery ball is not the sun, but stands for it. The psychic image is a symbol of the independent reality. The facts that the imagined sun may be but a foot in diameter, 
that the orbit of Jupiter may be but a quarter of a mile in length, that the twelve years of the revolution are imagined in a fraction of a second, are not referred to the meaning. The meaning lies in the proportions and qualitative characteristics only of the symbols, not in their absolute sizes, distances, and durations. The spatial is but the symbol. The reasoning in geometry presents such a typical variety of symbolism that a specimen may well be examined. "The sum of the interior angles of a triangle equals two right angles." In satisfying himself of the truth of this proposition the geometer uses as a symbol an imagined or perceived particular triangle. All the particularity of the symbol, the length of the lines, size of the angles, the color of the surface and border of the triangle and its position in time and space is neglected; but the symbol as a presentation consists of nothing but particularities, hence, in a sense, the whole symbol as a presentation is neglected, but in and through these particularities the universal meaning is known and held fast before the mind. The two fundamental truths of symbolism come out forcibly in the case of the geometer; for, $(a)$ the white-bordered triangle on the blackboard that existed for the space of ten minutes is not the triangle meant in the proposition; the symbol is not the meaning: $(b)$ "There is no royal road to mathematics," said the old master; only through the careful observation of the presentation-triangle can our consciousness discover and know the laws and concept of the triangle; the meaning is known through a symbol only. Notice that the meaning is always a concept.

In the region of higher truths the distinction between symbol and meaning becomes still more apparent, while the necessity of a symbol does not grow less. The case of causality, with which we began, shows this. The "pure thought" of Hegel has its symbolic presentation-accompaniment, which, however meager it may be, is still necessary. To me, at least, the "return in itself" is symbolized by something very much like a fish-hook; and when it is said that a conception "schlägt in seinem Gegensatz über," I see two parallel walls of which the one falls over so as to rest on its opposite. Without this pictorial furniture 
of the mind, it would be impossible for me to hold fast and connect the principles of the system.

T. H. Green, in his criticism of Herbert Spencer, expresses the hope (as it seems, with some misgivings) that the latter philosopher does not conceive of the mind in relation to the world as a "little box inside a big box." And yet there is reason to presume that Green himself, in company with all other ancient and modern philosophers, every day used some equivalent symbol to denote the relation of consciousness to the world. In our every day reasoning, do we not think of every man's consciousness as existing somewhere inside of his skull? But this pledges no one to materialism, for it may and ought to be but a symbol of the relation, and not the symbol that is used when exact thought is required. Descartes' theory of the soul as sitting astride the conarion and there, as at a central switching station, directing the forces of the body, was to him and his school the concept of the relation of mind and body ; to us a presentation involving this relation may very well be used as a symbol of the connection of the mind and the world, without binding us to this meaning.

May not meaning, or the concept, be a part of the symbol? That in the case of such higher concepts as causality, consciousness, and personality, the meaning is not, properly speaking, a part of the symbol, seems too apparent to need any further elucidation; but it may be supposed that in the cases where the meaning is the genus and the symbol a specimen of the genus, the case is different. That is to say, the seen triangle, drawn with chalk on the blackboard, somehow contains as a part of itself the conceptual triangle about which the mathematician reasons. This view rests either on a faulty use of language, or a superficial view of the case in hand. As a representation the triangle on the board has no concept about it; a stroke of the eraser, and it is gone forever. But this does not affect the concept at all. The heresy that the concept is any sort of a picture, must be carefully guarded against; and it is easy to see that a presentation can not contain as a part of itself the concept. The presentation-symbol may be wholly changed without 
entailing any change in the concept-meaning. Instead of a scalene triangle of chalk on a board, an isosceles triangle in imagination may be substituted, and still the meaning remains the same. The concept man is not the presentation a man minus length, color of hair, complexion, manner of dress, form of features, and position. For, abstract from all this, if possible, and still what is left is but fragment of a psychic image, an event in the thinker's imagination, something particular and arbitrary; while the concept man is not a psychic image at all, nor an event in any imagination, but a universal. This is, then, a distinctive difference between the meaning and its symbol. The meaning is universal, the symbol particular. As Dr. W. T. Harris proves, true human thinking involves in every thought the thinking of a universal. But it must not be forgotten that human thought also involves the particular as the symbol of the universal. Herein, then, lies the truth both of nominalism and realism. Nominalism was correct when it asserted that we can not imagine a triangle without giving some shape to the corners, nor a man without giving him a certain height, and that we can not think man or triangle at all without some sort of images. But realism was also correct when it asserted that the genus is logically prior to the species, and that general names have something more behind them than flatus vocis. In the concept-meaning world realism is true. In the presentation-symbol world nominalism holds good.

The chapter may be summed up as follows: that portion of the contents of consciousness which belongs to a thoughtmovement is always objectified, placed over against the ego as its other. All thought is materialistic in the sense that all thought is carried on by spatial and temporal symbols; these symbols are presentations. Meaning and symbol are inseparable. No meaning can be known without a presentation-symbol; and no symbol is of any value to the mind except because of its concept-meaning. The symbol is always spatial and temporal, the meaning always conceptual; hence, the meaning is not a part of the symbol, nor vice versa. 


\section{CHAPTER III.}

\section{Language, Symbol, and Reality.}

Symbolism and Language. - Language is the second remove from meaning, since meaning is symbolized by a "psychic" image, and language is the sign system used to represent these "psychic" images. Hence, language has nothing directly to do with the conceptual world, and is wholly "materialistic" in its principles. Words are signs of presentations, and of the processes of the presentation-complexes. Language is, accordingly, the symbol of a symbol. The word "triangle" stands for the presentation symbol, a particular psychic image of a triangle. This image is, again, the symbol of the concept triangle. The laws of language are therefore the laws of a special kind of symbolism of thought. It is a mistake, as fatal as it is frequent, to treat language as if it were a system of logic, as if it had to do directly with conceptual relations. Such a treatment must lead to one of two errors: either language is treated as some transcendental mystery, or logic is degraded into such a spatial and temporal affair as language is. The fact is, that these two errors actually have crept into both grammar and logic, and confused both. For example, grammatical predication has been confused with the judgment of logic, though the two are entirely distinct. Next it should be noted that language is the impression of thought rather than its expression. Language is not primarily a revelation of what the speaker thinks, but directions for thinking given to the hearer.* In speaking we do not reveal our own thoughts except incidentally; but we build up a thought in the mind of the listener. Speaking to a fellow-being is, in reality, treating him with great familiarity. We thrust ourselves into his presentation-world and raise in it presentations, connect and separate these presentations, and all, not as he will, but as we will. Hence the shock of indecency in speech to the chaste, and of profanity to the devout. It

*See Paul, Principles of Language, p. 111. Also Von der Gabelentz, Zeitschrift fur Volkespsychologie, VI, 378 . 
really does pollute their presentation-world, forces them to harbor, if but for a moment, unclean things. The auditor, in fact, to become such, must abdicate, for the time, his sovereignty over his own soul in favor of the speaker, since he must give the speaker right to raise any images in his world of presentations that the latter may choose to command. The symbolism which language expresses is hence necessarily in many respects limited and artificial as compared with the symbolism employed when we direct our own thoughts. Since language must be a mutually known, system, it must follow certain highways and continually come back into certain ruts, in order that hearer and speaker may not part company; when the thinker is alone he can ride cross country in any fashion he chooses. Hence it is radically false to assert that thought is impossible without language. The thinker can know the concept triangle through the presentation of a triangle, and reason himself to the proposition that its interior angles are equal to two right angles, without saying or thinking a single word. In fact, the geometer (at least the present writer) does not think in words when reasoning about figures. Deaf mutes whose sign language has been wholly inadequate to express higher thoughts, have still had such thoughts, if we may accept the testimony given by themselves after being furnished with written language as a means of communication.** Language is a description of the part of the presentation- $r$ world used as the symbol of thought. It is impossible that the description should condition the thing described.

Still it is true, that without language human thought would be barely human, and would never advance beyond the rudiments. Roads and ruts are limitations to the traveler and hinder him from putting his foot on the greater part of the earth; but still, without roads and paths, the traveler would not advance far. Every combination of symbol and meaning suggests a special insight into the relations of fact. In defining and labeling abstract ideas, language is of invaluable service. The image of the word in such cases generally becomes the presentation-symbol to

\footnotetext{
*See on this subject James' Psychology, I, 266.
} 
which the concept of the meaning is directly chained. When discoursing about "righteousness," "love," "beauty," and the like, introspection seems to show, that the word is often the only psychic image used as a counter. With visualizers this is generally the form of the word as printed. With this image the concept is directly associated; and so far do we often carry this association that the very wordform itself seems to us lovely, hateful, or contemptible. Isn't "traitor" an ugly word?

Artificial symbols.-This substitution of the printed or spoken word itself in place of some more natural symbol, seems to be carried further by certain minds. To them even "mutton," "tea," "sugar," and the like, are not represented, as with the most of us, by a presentation-image of a piece of mutton, a cup of tea, and a spoon of sugar, but by the printed form of these words themselves. But with these images are bound up the concepts of the objects, and the mind knows that they can satisfy hunger, and how they can be procured. Therefore, as has been well said, if these word-images make a man pay his grocer and butcher, why are they not as good as any other symbols? To a certain extent they are as good as any other symbols, and even better. They are definite, simple, and not liable to mutation during a train of thought, and thereby contribute much to its exactness. But on the other hand, they are artificial and as such their connection with the concept is arbitrary, depending only upon previous connection through natural symbols. Their hold upon the meaning is hence very slight, and sometimes incomplete. The full, round, central grasp of the meaning is lacking. Thinkers that employ such symbols to excess have a flat, uninteresting field of consciousness, fail to give relief to their thoughts, and have a fishy, clamlike coolness about them that fails to innervate either themselves or others. In a certain sense such Alexandrian commentators and thought-dissectors are very profound and thorough, they are sticklers for fine distinctions; but nowhere do they grasp with one bold effort of thought the life-giving, central principles whose infinite ramifications make the details what they are; and this because they let the bare image of 
their words in - tion, - hood, - ity, - ness, and the like, be their only symbols, and these symbols, having only a derivative connection with their meanings, give such a pale and lifeless reflection of the meaning, that it is not grasped in its full import.

Practical value of this distinction.-The division of thought into symbol and meaning is of great practical value. The original sin of all sophistry, bombast, and empty rhetoric is that they substitute splendor of image for grandeur of meaning. Herein lies the difference between true and false poetry. In true poetry, the glorious meaning shines and scintillates through the translucent symbol. But a symbol that symbolizes nothing is less than nothing, it is an abomination before the Lord. There is another evil to which especially philosophers are heir and that consists in mistaking meagerness in symbol for profundity. And so it has come to pass that the symbols of accepted philosophy are lean, lean as the seven lean cattle of Egypt in Joseph's dream; and if a thinker dares to put some more luxurious forms into his writing, his image-ascetic brethren are likely to treat these expressions as disrespectfully as were the fat kine in our figure by the lean. Exactness in vocabulary is a great desideratum, but this is often made an excuse for sterility of symbols, and sterility of symbols has the very opposite of the desired effect. A writer has invented a system of symbols that expresses his thought quite satisfactorily; he sticks to this symbolism through thick and thin, gloats over it, relies on its etymology, spins theories out of fine connotations of the words which were never taken into account when first the principle was symbolized by them, and so, before he knows it, he has a system of words instead of a system of thought; and this is the acme of idolatry ( $\varepsilon z^{\prime} \delta \operatorname{col} \alpha \alpha=$ form, hence form-worshipping); he is henceforth a quibbler in words. Hence the necessity of using various symbols, of continually changing the point of view to get the true parallax; hence the danger of the petrified poetry of language.

But language is a two-edged sword, and it is curious to note how, when avoiding one danger, we are liable to fall into 
the other. Picturesque writers are constantly in danger of the unconscious substitution of a metaphor which includes and ignores the problem in place of a solution. Even the famous "stream of consciousness" may be so used.

Meaning and reality.-Where shall we seek for the reality, truth, validity, which, supposably, is the real object of thought? First it should be plain that reality is not to be sought in the presentation-world as such. Neither in the present, past, or future, neither in perception nor in imagination or memory, does the presentation-world "touch the ground" of reality, but does most decidedly "float in the air"* of bare appearance. But do we not "come in contact with reality" in the present preception? Not a whit more directly than in memory. But is not what I see now and here a direct intuition of reality, while what I remember has but an inferred reality? Let us answer the question scientifically by an experiment. Place an object, your lamp, for example, before a mirror. Two lamps are seen. If the mirror is good, the eye can not distinguish the least difference between the two. As presentations they are equal in all respects. As presentations the one exists as indubitably as the other. Honestly, then, it is impossible to see any more reality in one lamp than in the other. The "direct" contact with reality turns out to be more than shadowy; for if the image this side of the mirror is real, then must also the image on the other side be so; and evidently if both images are nothing but presentations, then no other presentations are real either, even if they do not stand before a mirror. This can be shown in a simpler manner. Close the eyes. The whole visual presentation-world vanishes. Yes, not only seems to vanish, but really does vanish; for as percept it consisted in being seen and now all that was seen is not seen. If any part of this world was real, it was evidently destroyed; if nothing real was destroyed, then the real was never seen at all. This shows again how false it is to say that the meaning is a part of the content of the symbol. If it were, it would vanish when the symbol vanishes, be doubled by a mirror, and be non-existent when not per-

\footnotetext{
*The quoted expressions are from F. H. Bradley's Principles of Logic,
} 
ceived or imagined. Reality never meets us directly, not even in the present, if by "directly" is meant a sense-perception. All reality lies in the judgment about the phenomena. We judge that one lamp-image "is" the lamp and the other but the reflection of it. Therefore memory and perception, the past and the present stand on precisely equal terms so far as reality is concerned. "I see a house," means, I have a perception called a house, and I judge that there really exists an abode of man. The reality of the house lies in its relations; in fact, as a reality it is but a system of relations. But no relation as such is perceived by the senses. The fact that I see the house does not make it absolutely certain that it exists. Hallucinations are also facts. "I remember the house," means also that I have an image in my presentation-world called house, and that I judge said image stands for something real. But this time also I may be mistaken. In both cases, the presentationworld does not contain the real, but in both cases it is judged that the real is symbolized by the presentation; therefore, also, mistakes are possible in both cases. That there is a difference in the degree of certainty, is quite possible, but the difference is one of degree only. As a rule, it is doubtless true that we are more certain of the reality of what we perceive than of what we remember; but what is here contended for, is that the nature of the certainty is the same whether a perception or a memory is in question; and that this certainty is derived from a conclusion, a judgment. Nor must it be forgotten that though the general rule gives greater certainty to perception, this is by no means true without exception. Are there not in the life of every one certain memories of "the smiles and tears of bygone years" which appear so absolutely indubitable that we can not even imagine how a shadow of doubt should be cast upon them; while in our every day experience are there not hundreds of perceptions that at the time of perceiving them we are at a loss to know how to interpret?

The real and ideal in the conceptional world.-So we may take it for granted that the "psychic image" and the 
percept have nothing directly to do with reality.* The next question is, naturally: Do meaning and reality $\checkmark$ coincide? Or, in other words, is everything in the conceptual-meaning world real? An examination will show that if "real" is taken as opposed to "ideal" the real and the ideal are both in the realm of meaning. And not only so, but the real and ideal possess a great part of the territory of meaning (the conceptual world) in common. There are many meanings which are partly real and partly ideal. There are degrees of reality. Most of us, possibly, have a definite conception of the character of Micawber. Whenever we desire to be conscious of this meaning, we allow the optimistic but unfortunate creation of Dickens to appear a few moments on the stage of our thoughts and repeat his humorous wisdom. By watching the image-play we get the concept of Micawber's character, which as a concept is not spatial or temporal. We know, as we say, what sort of a fellow he was. This knowledge is the meaning of this $\checkmark$ symbol. Now it is evident that in our stricter and commoner sense of real, Micawber is not real. Hence, here is an example of a meaning that is not real, but ideal. Still, a closer observation will make it apparent that to a certain vegree even Micawber possesses reality. As a character of fiction, as a thought many have had, Micawber does exist, and is in so far real. Any number of degrees of reality can be given. That which exists of necessity, exists forever, exists now, did exist, shall exist, may exist, could exist, etc. The conclusion is, then, that the ideal and the real are found in the realm of meaning only. 


\section{PART II. \\ The Statics of the Symfolism of ThOUght.}

CHAPTER IV.

The Fundamental Thought-Forms.

Contrast of the content space and time.-The philosophy of the sentence depends entirely on the formal side of the presentation-world. There are two universal forms of thought that apply to the world of sense and imagination: space and time. Since Aristotle the distinction of form and content has been current among philosophers, and since Kant all speculation not hopelessly retrogressive has recognized time and space as in some sense the forms of thought.

These forms are antithetical and measure the widest contrast possible. The contrast of greatest importance is, however, not that the one is the form of "outer" perception and the other of "inner" experience, nor that some presentations seem to escape space, while none get outside of time, nor that time is of one dimension only and space of three. The fundamental contrast is deeper. Space is the form of plurality. Everything perceived in space is per-r ceived as being, if taken strictly, more than one. However small a piece of matter we perceive or imagine, it is evident that its upper half is not the same as the lower half. The north end, even of a molecule is not identical with the south 
end. If an atom is not a centre of energy only and without extent, its middle is one piece of matter and its surface wholly another piece having a totally different identity. We may subdivide eternally but we shall never find the absolute unit in space. The content of space (not space itself) is and must be essentially a plurality.

Exactly the reverse is true of time. Time is the form of unity. The content of time is one unit; everything perceived in time is a one of absolute identity throughout. The paper upon which I write is the same paper now as it was an hour ago. If $I$ tear it to pieces, these contain exactly the same matter as the whole sheet did before. Even if it is burned, the gaseous carbon, oxygen, and hydrogen, the smoke and the ashes contain precisely as much matter and the identical atoms of the paper. The world is one stupendous process of metamorphosis, not a series of creations and annihilations. Now, it may be objected that since it is possible to believe in the creation of matter it is a fortiore possible to conceive at least the possibility of annihilation and creation, and thus it would be possible to break in thought the continuity and unity of the content of time. The content before creation would not be identical with the content after. But this problem is solved by noting that if the world is created, it existed before its creation potentially in the wisdom and might of the creator. By believing in creation, we simply deny that matter is irreducible to something else and claim that it can be reduced to the energy of the creator, that, in fact, matter is energy. This may not be thought out explicitly by the believer, but is nevertheless latent in his thought. Every cross-section of time therefore, shows the same atoms, energy, and laws, every cross-section of space shows a different content from every other.

The contrast of time and space may be formulated as follows:

$\checkmark$ Every moment of time has a content identical with every other moment of time, but no point of space has the same content as any other point of space. It is necessary, to prevent a fatal misconception, to understand explicitly that when we claim that time and space are the forms of unity 
and plurality, we do not claim that time and space themselves are unities or pluralities. Either may at will be conceived as a plurality (of points or moments) or as a unity, a continuum. But the content of time is always conceived as being really a unity, and the content of space as a plurality.

It is to be noted that the questions of identity, plurality, and unity can not be decided by the perceptive faculties alone. We can not perceive identity. Hence the whole discussion on the forms of perception and imagination (the forms of the presentation-world) is based on something more than mere perception. It is instinctive speculation, the native philosophy of perception that is here involved. It were palpable nonsense to say that the universe appears at every moment the same, but it is certain that the world is taken to be the appearance of the sum of the same forces, laws, and atoms. Likewise it were sheer folly to assert that no two pebbles could be found exactly alike, or no two drops of water precisely similar, or no two places in the sky indistinguishably the same in color, but even a savage would not, and could not, on that ground assert identity between two objects. Conceptual identity is not the same as per- $r$ ceptual likeness.

The result of this contrast in science.-How much of what many devotees of natural science suppose a discovery by experiment is purely an a-priori law of the mind. The inpenetrability and infinite divisibility of matter is a direct corollary of the exclusiveness of space; and the conservation of energy, the indestructibility of matter, and nature's uniform conformity to law are derived from the inclusiveness of time. Even the laws of motion and inertia are nothing but special applications of the great psychological principles underlying presentation in time and space. The phogiston of the mediæval physicist was a piece of inaccurate thought and vanished just as much before the greater lucidity of the modern mind as by the aid of Scheele's balance. There is a story of a German professor who evaporated and distilled a quantity of water in a sealed copper retort for the space of many months, to prove the indestruc- 
tibility of every portion of the water in its every change of form. He might have spared himself the trouble. If it had not been in us to believe it by the very nature of consciousness, no amount of experimenting could have proven it. If experimenting could prove this, then the old gardener was also correct who was sure of another year's lease of life as soon as the month of March was past, since for eighty years he had noticed that whenever he lived over the month of March he lived all the rest of the year. In both cases induction is impossible, since it is impossible by the nature of these problems to get sufficient data.

All mathematics is based on these two principles alone, which in that relation are best expressed as extension and multiplicity, duration and succession.

In relation to symbolic presentation of thought, the two great presentation-forms of thought may be characterized as follows:

Space is the form whose content has multiplicity, extension, discretion, exclusion, outside-of-one-another-ness.

$\checkmark$ Time is the form whose content has unity, duration, continuity, inclusion, in-itself-ness.

\section{CHAPTER V.}

The Categories of Space.

As the basis of all grammatical categories there are certain logico-psychological categories based on the properties of the thought-forms just discussed. These categories are our next task.

The categrory of thing... The primary and also the fundamental category of space is Thing, or concrete individualized Number. Color and other qualities unite the infinite multiplicity of space into arbitrary, individualized aggregates which we call things.

Thing is the primary category of thought as well as of space; for the simplest way to conceive the world is as a collection of things. A child does not perceive at all before 
it sees things. At the very threshold of perception it encounters things. Atomism is the reigning philosophy in the nursery and in the hut of the savage.

According to the primitive judgment by which we apprehend Thing, we conceive it as existing in itself and not at all in another. Where the pen is, the ink is not; where the penetrating nail is, the board is not. Discretion, outside-ofone-another-ness is the very essence of our conception of Thing. The independent existent it might be called. This separating, individualizing of a part of the sense-continuum as a thing must be performed by the smallest child that distinguishes its mother's face from a stranger's. This being the import of thing, the next question is, For what is it used as a symbol? The answer is almost self-evident, For that which exists in and by itself, the self-existent, substance. To the end of time philosophers will think and talk of the most real and actual under the thought-form of thing. Protest as we may against the inadequacy of the symbol, we shall continue to talk of the mind, spirit, the subject, the ego, personality, the self-existent, as things. But with this distinction: in advanced thought, thing is merely a symbol, and a dangerous one, of the self-existent; in primitive thought and in much speculation that fain would be advanced, thing is the self-existent. To sum it up: the category of thing stands for substance, reality, identity, and discretion, for the self-existent.

Number.-True unity is not found in the space-presentation. That chair is not a true unit, it has parts, and the parts exist wholly in themselves and not at all in their neighboring parts. We speak of the presentation chair not the concept. Every particle of wood is imagined and, as far as perceived, perceived outside of every other particle, and no man can imagine, or perceive, wood where the glue is, or vice versa. To be sure the concept of the physical universe holds, as gravitation teaches, that dynamically every atom is present in every other, but it is impossible for perception or imagination to perceive, or imagine, this unity. To these faculties the space-world has real particularity and plurality, but only formal universality and unity. A equals 
not-B. Space makes the universe a collection of particulars. Hence physics teaches that the material universe is a collection of atoms. Logically, these must be held to be centers of force without size, for else the whole problem of adhesion and attraction remains untouched and unsolved in every atom. Why the north half of an atom hangs to the south half, though the north half only touches and is wholly outside of the south half, needs as much explanation as why the south hemisphere of the earth adheres to the north. But the average physicist's understanding is satisfied when it has outstripped his imagination, and so he generally concludes that the atoms are "very small," "probably spherical," and "of the same size." "If a pin's head were magnified to the size of the earth, the atoms would probably not exceed a pin's head in size, and might be so far separated from one another that an inhabitant on one might need a tiny telescope to see the next." Very likely indeed! This picturesque philosophy may have its attractions and is certainly harmless. But all we have to do with it at present, is to point out that it is an unsuccessful attempt to get at unity where in the nature of the case none can be had. The world of space-presentations is essentially a plurality, and hence space gives us number. Number is, therefore, a necessary attribute of space-presentation. An arbitrary, formal unit is taken, and by the aid of this, quantity is expressed as a finite number. Substantives, as the signs of things, accordingly, often have the property of expressing number by their form.

Hence number is the fundamental attribute of thing. Number as the fundamental attribute, however, is multiplicity without unity. True grammatical and mathematical number requires, in addition, unity. Something must be taken as the unit before any finite number arises. In order to get grammatical number from the unitless discretion of space we must invent an arbitrary unit. We must choose a resting-place somewhere for a division that else would be infinite. On this fact Bishop Berkely based his claim that number is a wholly subjective affair. What is the number of a library? The number of shelves, books, chapters, lines, 
words, or letters? Using the terms of the Hegelian analysis, we should call grammatical and mathematical number Anzahl, which is the resultant of Zahl (here multiplicity, discretion), and Einheit (here the arbitrary unity).

We do not class number as a special category, since it is simply the abstraction of the category of thing. Things are simply incarnate number. Things are expressed in language by substantives (nouns and pronouns).

The category of quality.-Amount and color of light, taste, smell, and the qualities perceived by tactual perception (the "feel" of things), as smoothness, hardness, heat and the like, are the individualizers of space. Quality, in short, reduces abstract divisibility and discretion into things. Qualified discretion $=$ concrete number $=$ things, objects. A unit with a quality is a thing. The second category of space, quality, is the unifying factor in the abstract plurality of space.

Quality is conceived as existing in another, as the dependent existent. It is a fractional thing, the continuity in the space-world in spite of its fundamental discreteness. Tastes and colors are typical qualities. They exist in space and still they do not occupy space. The sweetness of sugar does not hinder it from being white in the same space, but one thing hinders every other thing from being at the same place. Qualities are dependent in their existence. We can $r$ always imagine a thing as existing after the destruction or mutation of certain of its qualities; but we can not imagine a quality surviving its thing. Hence quality-presentations are used as the symbols of attributes. Quality is expressed by the adjective.

Next of the categories of space comes

Position (or space-relation).-B stands north of A. In perceiving $\mathrm{A}$ and $\mathrm{B}$, we unquestionably also perceive the northness. The book is on the table. The book and the table can not be perceived without also perceiving the relative position of the book to the table; but where is this relative position, this on-ness? Not in the book alone, nor in the table certainly, nor in the space or line between the book and the table; for, if book and table were removed, there would be no on in the line that had been between. Evidently, 
here is something that exists not in the self (book) as the thing, nor in the other (table) as the quality; but in a higher unity of self and other. Position is the highest category of space-presentations, and is used as the symbol of related beings.

The category of position is the result of an application of the laws of time (continuity) to space. Matter is wholly outside-of-one-another. Molecule $\mathrm{A}$ has no business, and can have no business, with molecule $B$, according to the geometric conception of the universe. "A thing can not act where it is not," said the ancient philosophers complacently. (The dynamic conception of the universe reverses this judgment, but does so by conceiving the universe not a collection of things at all, but as a system of forces.) As soon as we speak of a relation between things, we have made things the members of a higher unity, the universe.

To prevent a fatal misconception and consequent objection, it is to be noted that both number and position may be thought of as quality (ex. five, former) and consequently be represented by adjectives. This can be done, however, only after a change of category (see p, ), that universal practice in language, of thinking what properly belongs to one category under the form of another. It is evident that before number can be thought of separate from thing, it must by a violent abstraction be degraded from its position as the fundamental of thing.

Position, or space-relation, is represented in language by "cases" and prepositions. All prepositions and cases represent, hence, when not used figuratively, and even then in the presentation-world, nothing but space-relation.

Review of categories of space.-The fundamental category of thing in a way includes the other two. The category of quality is more abstract, and is the reconciliation of a contradiction. It introduces a lower unity in the essential plurality of space. Position is the application of the laws of the antithetical thought-form (time) to space. It consists in a higher unity of plurality. Thing $=$ existence in itself, quality $=$ existence in an Other. Position $=$ existence in the union of Self and Other. 
Summary of categories of space, or presentations of extension.

$\left.\begin{array}{c}\text { Category. } \\ \text { I. Thing.... Discrete, existing in itself; inde- } \\ \text { pendent being; occupied space; } \\ \text { concrete number. }\end{array}\right\} \begin{gathered}\text { Symbol of } \\ \text { Substance, } \\ \text { Identity \& } \\ \text { Contrad. }\end{gathered}$

$\left.\begin{array}{r}\text { 2. Quality.. Existing in another; dependent } \\ \text { being; in space, but not occupy- } \\ \text { ing it; a lower unity in plurality. }\end{array}\right\}$ Attribute.

3. Position...Space relation; existence in a $\left.\begin{array}{l}\text { higher unity. Application of } \\ \text { the laws of time to space. }\end{array}\right\}$ Relation.

\section{CHAPTER VI.}

The Categories of Time.

The category of event.-The primary category of time is the event. Here event is used in its broadest signification. According to this, Napoleon was an event as well as a thing, and similarly we would speak of the existence of the pyramids as an event. Any individualized portion of time is here called an event. To see the world as a series of events is probably the second phase of human consciousness in its development from infancy. First, as we noticed, the child thinks the universe as a collection of things; next, it probably rises to the category of event, and the universe becomes a continuous chain of events.

The "double dimension," or double thought-form of an event. - There is a notable psychological difference between the first category of time and the first of space. Though in the nature of things it is impossible to have a space-occupying content that does not also occupy time, since, for example, a pyramid or a soap-bubble can not be seen, or imagined, at all, without being seen, or imagined, during some period of time; yet it is possible wholly to withdraw the attention 
from this fact and hence be quite unconscious of it. But on the contrary it is not possible to let the attention rest exclusively on the time-content. We can not imagine or perceive an event, or happening, without giving some attention and full consciousness to the fact that it is some thing that happens. An event is always the event of some thing. We can not fill duration without a thing, but we can fill space without being conscious of having to do with events. This psychological fact determines two very important things in grammar, the subject and the complement (predi$\checkmark$ cate noun or adjective). Every true event-word ("finite" verb, participle, or infinitive) can take a subject. That is, wheneve" we express an event we must express, or imply, some thing as subject of the event, since it is necessary in thinking an event also to think its subject.

In determination, (the "modifying" of another element) also, this double nature of the category of event plays an important part. A thing is determined (modified) by spacepresentations only, but an event may be determined (modified) by both space and time presentations. What a thing is at this moment it is, no matter in what manner it has passed the eternity a parte post, and is to pass the eternity to come. But the case is different if the question is of an event. Duration is determined not only by how it endures but also by what it endures. To endure for forty centuries in absolute quiescence is not, perhaps, so very sublime a thought if the thought is of a pebble, but it is awe-inspiring if conceived of a pyramid. Thing is, then, determined only in one "form" (the only one it has), the "form" of space. Event, on the other hand, persists in having two "dimensions," or forms, time and space, although its proper thought-form, that on which the emphasis is laid, is time; and hence event may be determined (modified) both as to time and space. This explains the "predicate adjective" (or attribute complement) and "predicate noun." This adjective element does really determine (or, if the term is preferred, qualify) the verb of the predicate and not directly the subject. Ex. "The diamond is brilliant" =-: The diamond has a brilliant existence, The diamond is a brilliant event. 
Existence is predicated of diamond. This is, however, a wholly uninteresting predicate, because it is so wide. Hence it is determined spatially by the mention of the quality brilliant. The objection: "We are not conscious of predicating existence at all in this case; is is a mere copula," will be answered later.

Duration.-An event is a concrete individualized duration just as a thing is a concrete individualized number. Hence $\checkmark$ duration is the fundamental property of the first category of time just as number is of the first of space. An event may $r$ be spoken of without reference to the time it endures, as go, went, it, iit; and it may also be asserted to have occupied some time, as was going, ibat. Accordingly there are twor species of verbs and expressions of events in reference to duration: (a), aorist, as vehit; (b), progressive, as vehebat.

Grammatical duration corresponds in the time-form to grammatical number in the space-form. The singular and $r$ plural in number corresponds to the aorist and progressive of duration. The correspondence is, of course, antithetical. If we desire a refined subtlety in our nomenclature, we may call number as a fundamental property of thing, discretion, and likewise duration as a fundamental property of event, continuity, and keep number and duration as terms for the more concrete grammatical properties.

The category of manner or variation.-Continuity, or abstract $r$ duration, alone would be one empty, limitless sameness, worthless and uninteresting to man if there were not a secondary category to individualize the first. This is variation, or manner. If all events happened alike, there would be no events. The variation, the change that diversifies duration, plays the same rôle for event as quality does for thing. Just as the infinitely plural points of space are united into aggregates called things by the second category of space, viz., quality, so, and yet contrariwise, the infinite continuity of time is broken up into fractions called events, by the second category of time, variation. For example, how do we perceive extension in a thing, say a clover leaf? By perceiving a green surface with a trilobed outline. But this green surface is where the clover-leaf ends and nothing 
begins. In seeing the form of the leaf, we see the edge where there is clover-leaf no longer, but something else, air or table-cloth, perhaps. Hence to perceive a clover-leaf means to perceive where it ends, to perceive what is not a clover-leaf. The space occupied by the leaf is absolutely hidden from my perception. If I touch it, my fingers cone only to where the leaf is. Hence the surprising result, that the negation of a thing is just what makes it a thing. The perception of substance is therefore the perception of the very thing that is not substance, but its attributes, its determinations, its negations. To sum it up: extension, number, the essence of the space-form, is known to us in objects, things; but thing is known by negation of extension, and number by its limit; hence thing reveals extension by a seeming denial of it. The case of the time-form, and its essence, duration, is analogous. Duration is known only by variation, change, motion; were we and the world changeless, there would be no time. But change is known by the denial of duration. How could change occur if something in the changing object did not pass away, and something new and different take its place?

It is to be noticed that variation is the true name of the category, not motion. For motion requires duration as an element. At first sight motion seems the very antithesis of duration. But it only seems so. Motion would be impossible without duration. If an apple is to fall, it must be the same apple on the ground as it was on the bough. To-night we see a planet in one sign of the Zodiac, and a week hence we shall see it in the next; but before we judge it has moved from the one sign to the other, we satisfy ourselves that it is the same planet that we observed on the former night. If a row of electric lights placed very closely together are lighted and extinguished rapidly in succession, it will appear as if one ball of light traveled the whole length of the road; but we judge this appearance of motion to be an illusion, since the first light is not the same as the last, or as any other light.

Every event, then, is cornposed of the fundamental element, duration, and the secondary element, variation. If the emphasis is laid on duration, we get existence. Ex. 
Xerxes was king. His endurance as king is emphasized, but we could not know duration without at least some variation. If the stress of consciousness falls on variation, we get motion. Ex. Xerxes fought with Greeks. Verbs may accordingly be divided in reference to variation and duration, into two classes, substantive verbs (static verbs) and motion verbs (dynamic verb).

The first class expresses:

$$
\text { Event }=\left\{\begin{array}{l}
\text { Duration } \\
\text { Variation }
\end{array}\right\}=\text { existence. }
$$

The second class expresses:

$$
\text { Event }=\left\{\begin{array}{l}
\text { Duration } \\
\text { Variation }
\end{array}\right\}=\text { motion. }
$$

The event, unquestionably, includes that which endures, $\checkmark$ but just as certainly there is something in motion that perishes. To be sure, this is thought of as the unimportant, the accidental, sometimes as the unreal, the seeming; but still it is something. This something when abstracted from the event is the circumstance, the manner, the mode, the variation. Variation may thus be defined as that which varies in the enduring. It is, accordingly, the seeming negation of the very essence of the time-form (duration, continuity), just as quality is the apparent negation of discretion. The event is thought of as that which exists in another and still exists in itself. The child, the savage, and the savant look upon the bird and its flying as two different affairs. The bird's flying can not exist without the bird, but still the flight of the bird is not a part of the bird, as a quality is a part of the thing. The bird is just as much a bird when it alights. Here event (motion and existence) is distinguished from quality. A green apple that turns red is not fully the same apple as before; but the falling apple and the apple after it has fallen are fully the same apple. We speak now of the natural, unsophisticated way of thinking. Evidently anything can be thought of as a quality. Wer may then conclude that quality is dependent existence in 
$\checkmark$ another, event dependent self-existence in another. In other words, motion and existence are thought of as both dependent and independent at once. Now comes the $\checkmark$ important conclusion. Therefore variation is dependent being of dependent being, or a dependent being of the second order. Hence variation (manner) is a category that can be used with any dependent category, as motion or quality, but not with a truly independent category, as thing. Things have no manner. This is the reason why, in the signs of the categories, adverbs can modify both adjectives and verbs but not nouns. Manner or variation, the second category of the time-form, has as its sign the adverb.

Variation introduces a secondary plurality in the fundamental unity of time, just as quality gave a secondary unity to the fundamental plurality of space.

\section{CHAPTER VII.}

\section{The Categories of Time.}

(CONTINUEn.)

The Category of Succession. - In order to make anything out of time, we have seen that we must get a plurality into its unity. But under variation this multiplicity was still avowedly secondary. If, however, we consistently apply the fundamental law of space to time, we get a view of duration in which discretion is primary - the world becomes a series of events, a succession. The category of succession appears in grammar as state of verbs and as conjunctions.

State.-We have now discussed the two sides of motion and existence (the event), the enduring and the perishing components. But do not motion and existence themselves have an absolute beginning or end? Every day we see objects begin to move and again come to rest; every dav things "spring into existence," and again "pass away." How, then, can motion or existence be said to represent the enduring? Simply because we are so made that we can not 
believe that the apparent end of motion (or existence) is the end of it. Here we simply refuse to believe our senses. The contrast between time and space is in this respect complete. Everywhere between the beginning and the end of an event, the event is considered the same, and even before the beginning and after the end of the event proper it is believed to exist in some other form ; it is imagined to exist as a motion too small in oscillation to be perceived. On the other hand, where a thing ends (in space, not in time) it does end, and nowhere between the limits of a thing is the thing the same. A pin's head is not the same piece of metal as its point; no, if molecules have size, the south side can never be identical with the north side of a molecule. It is therefore events as the revelation of force that we consider. A force can exist in three states: (I) not yet revealed as an event, a potentiality; (2) being revealed in motion,* an actuality; (3) having been revealed by motion,* a result.

It is to be noted that from the point of view of the presentation-world, it is perfectly proper to speak of motion, not force, as enduring. Force can not be imagined or perceived in its purity. It is a concept. When force exists as potentiality or result, it is accordingly pictured by the imagination as some sort of small motion that escapes common observation. This pictorial reasoning is carried into physics, and so all energies are converted into modes of motion; and heat, the form in which the result of motion often appears, is gladly accepted as a mode of molecular motion. Since we thus move in the symbol-world, we may with propriety say that an event may exist in three states:
a) potential,
b) actual,
c) perfected (as result, real).

Verbs and participials ought to furnish signs for these distinctions. Potentiality is generally represented, not by a form of every verb, but by a special class of verbs, here called the potential verbs; these are in English may, can,

*All events are revealed by motion, hence we use "motion" alone in these cases, where at first sight one would expect "event" or "existence and motion." 
must, need, will, shall, and perhaps a few others. These are distinguished in English by a peculiar inflection. There is in English no corresponding infinitive or participle, which renders the English very poverty-stricken in comparison with the German and Swedish in so-called potential mood combinations. In English a marvel like the following is infinitive supine infinitive impossible. (Swedish): Jag skulla hafva kunnat vilja se. (I should have coulded will see.) This means, as near as the rude English can express it: I might possibly have liked to see. The future participles* of Latin and Greek and the future infinitives $\dagger$ of Greek are also signs of potentiality, and not at all future in nature. Recturus est, he is about to rule. Recturus expresses the present potentiality, not a future actuality. His present state is such that ruling is a

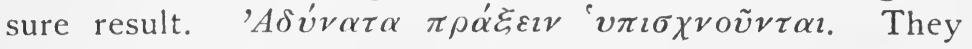
promise to be abont to perform impossible things. Strictly speaking, they do not promise to perform ( $\pi \rho \alpha \boldsymbol{\alpha} \tau \varepsilon \imath \nu$ ), but to be in such a state now that performance will necessarily follow. This is, of course, equivalent to promising a future actuality, but grammatically it is not the same. All future tenses might be explained as potential; but for reasons which will appear when we arrive at assertion, it is proper not to do so with the finite verbs.

Actuality is expressed in English by the present and past tense of the verb, the present participle, and the infinitive; in I atin by the present, first future, imperfect, and perfect historical; in Greek by the (indicative) present, future, imperfect, and aorist, with the exception that the aorist participle represents an action as perfect except when the chief verb is in the aorist.

Result, or the perfect state, is represented in English by the perfect passive participle alone. In Latin by the logical perfect, pluperfect, and future perfect. So in Greek. English, modern Greek, German, Swedish, NorwegianDanish, Icelandic, Anglo-Saxon, Gothic, French and Spanish have, in spite of the numerous perfect tenses in their

*Participials will betreated of together with verbs when practicable, thougl the reader is warned not to suppose that the participial is a true verb.

thatin has no true future infinitive, since for reasons already given, we recognize no forms of the verbs or participials composed of two or more words. 
grammars, no form of the finite verb which expresses perfect action. They use a circumlocution with have and a participial. This seems to be a Germanic invention, which the Viking conquerors of the world introduced even into the Romance and Hellenic tongues. The analysis of this interesting construction must be deferred till participials are reached.

State compared with case. - The state of the verb corresponds to the case of the substantive, but corresponds, as we would expect, in an antithetical manner. The case determines the space-position of the object as measured from the governing word.

Stylem cepit. The $m$ in stylem shows the space-position of stylem in relation to cepit. The pen was the goal of the motion of taking. Likewise, the state of the verb determines the time-position of the event, measured from the time of actualization of the event. Ex., scripsit. The position of scripsit is determined as being that of result. The measuring is backwards to its own actualization, scribit. Hence scripsit is one of the succeeding members to scribit in the timesuccession.

While, thus, case represents space-position and state time-position, there is a very important contrast between the two. A thing measures its position from another. In space only one position is occupied by one thing. But an event determines its place in the time-succession from itself, since it is from its oron actualization that the state of the verb is determined. Teleologically there is also a contrast.

The position of a substantive is determined in order that the substantive thereby may limit the meaning of the word governing. Ex. John's house. Fohn's is determined by 's in order that Fohn's may limit house. The time-succession. of the verb or participial is determined for the sake of the verb or participial itself.

The tense or time of the verb is a property that also in a. sense corresponds to position in space, and is also a form of succession. But it belongs really to the whole proposition, and is discussed under Assertion. (See Part III, "Syntax," Chap. IX.) 
Succession as represented by conjunctions. - Conjunctions correspond to prepositions. Time is essentially the form of continuity; but if we force into it a plurality which never, however, can be more than arbitrary, just as the unity of space-presentations is only arbitrary, its duration becomes succession. Words like if, because, that, since, though symbolize, to be sure, cause, condition, purpose, and the like, but as presentation-signs they all alike stand for succession. For how can, for example, cause and effect be symbolized in the sense-world? Only by succession, as Hume so amply proved. We can not see, hear, smell, taste, feel, or imagine more of cause and effect than that B happens after A. But such is the human mind, that through this symbol in the presentation-world we know the concept of cause, and its reality. Purpose comes under the same law. All we can see, is that a certain being does action $\mathrm{A}$, and $\mathrm{B}$ follows. Then we conclude that in the mind of the agent there existed ideally the result $\mathrm{B}$, that this result was desired, and that, in order that it might be realized, action $A$ was undertaken. The etymology of the terms used testifies unmistakably to this truth: "in order that," "it follows," "since." This is also generally admitted; but what is apt to be overlooked is that to this day, when we use a conjunction, we arrange the propositions connected by it in succession*, and this succession symbolizes to us purpose, result, condition, cause or whatever may be the higher, conceptual meaning of the word.

Conjunctions connect propositions only, and this for the reason that within the proposition there is no succession. But should there exist any time-succession between the parts of the proposition, this is symbolized as a space relation by a preposition.

Summary of categories of time.

$\left.\begin{array}{l}\text { Category. } \\ \text { I. Event...... The enduring; self-existing, } \\ \text { still depending on another. }\end{array}\right\} \begin{aligned} & \text { Symbol of } \\ & \text { Force. }\end{aligned}$

* This succession is not the actual succession of utterance, but an ideal succession. 
2. Variation... ( $\left.\begin{array}{l}\text { or Manner) The variable in } \\ \text { the enduring. }\end{array}\right\}$ Modality.

3. Succession...Time-relation; the laws of space applied to the content $\}$ Relation. of time.*

\section{CHAPTER VIII.}

The Categories in General.

Abstraction.-Psychologically, the positive side of all thought is attention and the negative side abstraction. By abstraction we mean, in this connection, the partial withdrawing of consciousness from a portion of its field. In order to be conscious of a thing, we must concentrate our attention on that portion of the space-continuum, and consequently withdraw it from the rest of space. As we have had occasion to point out before, perceiving a thing is to perceive what is not the thing, but its qualities, limitations, negations. Of this we are, however, not directly conscious. In perceiving a thing we centre our attention on the thing and include the environments of the thing in the "fringe" of consciousness. The sphere of attention need not be greater than the thing itself, however. On the contrary, we can not think an event without also thinking the thing that happened. We can place the center of attention in an event, but we can not limit the sphere of attention to an event alone. Writing can not be imagined or perceived without including the presentation of a pen, though it is quite possible to give the major part of the attention to the movements of pen and fingers, and only a small portion to the thing-presentations, pen, fingers and paper. The sphere of attention in the case of thing and event may be represented thus:

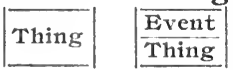

$V *$ Wlien words or phrases not propositions seem to be connected by conjunc. tions, this can be explained by ellipses. 
Neither can abstraction be complete in the category of quality. We can not picture beauty without also picturing a beautiful thing. Attention can be centred in a quality, but it can not be exclusively occupied with a quality. The abstraction from the rest of the universe, from what is not that quality, can not be complete. Quality is always a portion of a thing. Because of this similarity in demanding the presentation of thing as forming a subordinate portion of their sphere of attention and their consequent inability to stand alone in consciousness, event and quality may be called the secondary categories, and thing the primary category.

The ielation of thing to event is, however, quite different from its relation to quality. The quality is a part of the thing, the event is only united to the thing. The bird and its flying are two, not one. The flight is not a part of the bird.

Variation, or manner, can not be perceived or imagined without the accompaniment of the content of at least two other categories, thing and event or thing and quality, since variation inheres in quality and event and can not, accordingly, without one of these be presented to consciousness. As these can not be presented without presenting thing, there can be no presentation of variation without at least two subpresentations, either event and thing or quality and thing. Position (space-relation) and succession (time-relation) require also at least two other presentations, viz.: those between which the relation exists. Hence in the case of these three categories, variation, position, and succession, the sphere of attention can not be restricted by abstraction to less than three categories. Hence these may be called tertiary categories.

Change of category.-We are not satisfied with the natural and direct usage of the symbols. Often a symbol is placed in a category which it suits only indirectly and artificially. The Thirty Years' War, for example, is not always, indeed seldom, thought as an event (they fought for thirty years), but generally as a thing (war). Motion, action, being, in fact all nouns expressing events, are examples of 
what naturally belongs to the category of event being brought under the category of thing.

The psychology of the change of category is a rather abstruse subject, but the following seems at any rate established. As has just been remarked, it is impossible to imagine any event or quality alone. A thing is also always present in consciousness. Take the rather commonplace lines: "O the world is full of beauty when the heart is full of love." We can not imagine beauty; what we do present to our minds is beautiful-thing. But though a true thing-presentation is thus present, its right and essence is neglected; it is treated as if it never existed, and its thingness (space-occupying property) is transferred to the quality. The quality is henceforth a thing in thought, and has all the space-occupying properties of a thing. Beauty must be thought with spatial dimensions, in order to be that with which anything can be filled. Ex. "Mohammed severed with a sharp blow the brazen serpent's head from the tripod." Here blow is symbolized by a moving arm and sword. That is to say, the center of attention and interest is the motion, but the arm and sword, though not in the center, are still inside the sphere of attention. But, although in the sphere of attention, their existence is not recognized; on the contrary, the space-occcupying properties and the independent existence are transferred to the event, the blow. Thus the event blow becomes a thing. This is the regular process in the change of category, and may thus be summarized: The portion of consciousness that falls outside of the category which contains the center of attention, is ignored in the combination of thought and has no value in the organism of the sentence. But the properties of this neglected portion of consciousness are transferred to the portion containing the center of consciousness, and hence this latter portion is changed into the category of the neglected part. Very often, however, this regular process is interrupted, it seems, by the substitute of wholly artificial symbols. Thus, to the writer, such concepts as virtue, goodness, and hope seem to have as symbols simply the visual image of the printed English word. Others, however, like sorrow, speed, rude- 
ness, and color, seem in any case to follow the regular process in the change of category. Sorrow is a bent head with tearful eyes; speed is a horse galloping, of which the position of the legs is the most prominent feature; rudeness is an ill-mannered, swaggering boor, and color is represented by a colored surface, generally of a reddish or orange tint. Analyze speed, for example. We become conscious of speed by imagining the event of moving, and moving can not be perceived or imagined without a thing moving. The direct category of speed is variation, and its word is quickly. In this case, then, we must be conscious of $a$ ) variation; $b$ ) event; $c$ ) thing. But the event and the thing, though present to consciousness, are ignored as parts of the thought, while the thingness of the thing is attributed to the variation, and that presentation thereby changes into the category of thing, - from being quickly, it becomes speed.

Change of category is generally towards the primary category. Ex. Internal (quality, secondary) from in (position, tertiary); deed (thing, primary) from do (event, secondary); neighborhood (thing, primary) from by (position, tertiary.) But the change from event to quality and from position to variation are also very common. Ex. active from to act; near from by.

Comparison of the categories. - Thing is a limited portion of externality, viz., space, individualized by quality. The content of this portion of the continuum of space is conceived as an infinite number of atoms.

Event is a limited portion of time individualized by variation (change). The content of this portion of the continuum of time is conceived as an infinitesimal fraction of duration.

Hence, thing is qualified, limited, concrete number (or discretion).

Hence, event is modified, limited, concrete duration (or continuity).

Each category is a thought-form sufficient to include the universe. Each is a philosophy.

Thing = The universe is a collection of extended objects; matter $=$ Materialism. 
Quality $=$ The universe is a system of abstractions (perseitates $)$, properties $=$ Scholasticism. $\quad($ Note the supreme position given to substance and attribute by the Scholastics.)

Position (space-relation) $=$ The universe is an organism of separate individuals that are yet in a sense one $=$ Leibniz' Monadology. (Each monad is absolutely distinct and outside of every other. Still there is a monas monadum including them all in his pre-established harmony.)

Event $=$ The universe is One $=$ Eleaticism, pantheism.

Variation $=$ The universe is an eternal variation of an invariable energy governed by invariable laws. The philosophy of modern natural science.

Succession $=($ time-relation $) . \quad$ The universe is relation; a plurality because it is a unity; is freedom, since it is selfrelation. $=$ Neo-Hegelianism, Boströmianism.

Concrete number individualized makes thing.

That which unites the fundamental discretion of space is quality.

Things have in grammar number, because of the fundamental discretion of space.

Grammar has "cases" and prepositions, because of the relations resulting from the unity introduced into the discretion of space by the category of position.
Concrete duration individualized makes event.

That which divides the fundamental continuity of time is variation.

Events have in grammar duration, because of the fundamental continuity of time.

Grammar has "states" and conjunctions, because of the relations resulting from the plurality introduced into the continuity of time by the category of succession.

Summary of Categories.--

A. Categories of space.

I. THING........ That which is self-existing, and independent. Category of exclusion, plurality, particularity.

II. Quality ..... That which exists in another, and is dependent. 
III. Position.... That which exists in a higher unity of self and other. The contents of space viewed after the laws of unity belonging to the content of time.

$B$. Categories of time.

I. Event........ That which is self-existent but still dependent. Category of unity, continuity, universality.

II. Variation or Manner.-That which exists in another dependent being; the changing in the enduring.

III. Succession...That which exists in a lower plurality. The contents of time viewed after the laws of exclusion belonging to the content of space. 


\section{PART III.}

\section{The Dynamics of the Symbolism of Thought And the Elements of SyNTAX.}

\section{CHAPTER IX.}

\section{Assertion.}

Introductory. - Syntax has the same relation to the dynamics of thought as morphology (the science of the forms of words; included generally in etymology) has to statics. Theoretically, the perfect division is: statics (or categories), dynamics, morphology (or "etymology") and syntax; but for practical reasons it has been found better in the present case to combine dynamics and syntax. Every question of syntax can be understood after the corresponding part of dynamics better than if syntax formed a system of its own. Hence Part $\mathrm{V}$ will be a treatment only of that portion of syntax which could not well be treated before morphology.

The dynamics of the symbolism of thought is the science of the combinations and uses of presentations as the symbols of thought. Syntax treats of the uses and combinations of words as the expressions of this symbolic thought.

In one sense, syntax and dynamics are the same as morphology and the science of the categories, only seen 
from another point of view. The subject-matter of morphology is the word as the presentation-sign; of statics (science of the categories), the presentation as a conceptsymbol. The subject-matter of syntax is the sentence (a combination of words), and of dynamics, the presentationsymbol of thought (a combination of presentations). Hence statics and morphology deal with the tools of articulate thought, while dynamics and syntax treat of the use of these tools. But in describing the tools it is natural to state for what theý are used, and in treating of their use it is necessary to refer to the form of the tools. Briefly, then, statics is a description of the brick and mortar of the symbolism cf articulate thought; dynamics is a treatise on the masonry of such thought.

Dynamics falls into two great divisions, construction and assertion. The former contains the principles of the formation of presentation-complexes with symbolic meanings in the hearer's mind ; the latter is the assertion of the relation between the ideal content of the proposition and reality.

Assertion is the most vital property of the verb, and the most important function of the sentence and of the symbol of thought. And yet, strangely, it has been almost wholly neglected, and even mistaken for predication. To get a clear conception of what is meant by assertion will necessitate a discussion of a question of metaphysics.

The ideal and real in relation to assertion. - To the unsophisticated mind nothing is more obvious and indisputable than that there is a fundamental distinction between thought and reality. Whatever may be the merits of the ontological proof of God's existence, it is certain that Anselm and his followers have not made many converts by its use among those who boast of common-sense. What is only imagined and conceived is by the world generally placed in sharp antithesis to what is real. After a few lessons from Berkeley and Kant, the neophyte in philosophy is apt to declare for the other extreme, and regard the whole universe as a clever dream. It is not our present purpose to attempt to sit in judgment upon the relative merits of idealism and realism; our present purpose is to show that whatever 
may be our view of the world of sense, we must still make a distinction between the ideal and the real, between the fancied and the real, or however we may denominate the distinction. As Kant said, there is a decisive distinction between having a hundred thalers in the pocket and simply imagining a hundred thalers. Even Berkeley did not believe that his friends would be annihilated when he ceased to think of them. But to formulate this distinction so that no one shall take offense is a difficult matter. First, however, we notice that everything is real, when taken for what it is; for, strictly speaking, nothing can be unreal. Dreams are real as dreams, an illusion is a real appearance. Reality lies in the judgment. If the traveler judges that the mirage of the desert is a mirage, he knows it as a reality; it is as real a presentation as the sand under his feet. Hence reality lies in the relation of a thing to others. Only when the wayfarer judges that the water in the mirage has such a relation to him that it can slake his thirst, does the appearance become in so far unreal to him.

There is, however, another use of the word in which we are more directly interested here. We use real in contrast to ideal. Real is that which does not depend for its existence on any one person's thinking; not real but ideal are the images with which thought works. This use of the word real may be faulty, but is the common usage, and the distinction aimed at is certainly important. The speaker raises a series of presentations in the imagination of the hearer, with the intention that the hearer shall give to them their true import. But not for one moment does speaker or hearer suppose that said images are real. Most people, if interrogated, would reply that these presentations are unreal figures that peep about inside the skull of the listener. We know better, perhaps, and do not locate minds in skulls; but still we must recognize the essential difference between the real and that which is only thought of. The listener's constructing an image, or the speaker's commanding it to be constructed, does not make it real, nor does it make the meaning of the image real, nor increase the listener's knowledge. If in some manner, however, the speaker can express 
to the listener the relation between the image, its meaning, and reality, or how far the ideal world which the listener has just construed has its counterpart in the real world, then the listener's knowledge is thereby increased. This is assertion. A evokes in the mind of $B$ the form of B's horse, he may combine with that thing-presentation the motion-presentation running, and yet $B$ would have only the picture of his horse running, and would not know whether his actual horse were running; but the assertion that the union of run and horse has its counterpart in the real world, is the assertion of the sentence, and is its most important function.

Definitions of asscrtion.--Assertion is the expression of the relation between the real world and the ideal content of a clause or sentence; or, assertion is the expression of the relation subsisting between the thought-complex construed by the auditor at the direction of the speaker, and the real world; or, assertion is the expression of the degree of validity possessed by the construed thought-complex.

How expressed.-Assertion is expressed by the verb, but in this it is sometimes aided by the arrangement of words, and by particles, such as the question particles in Latin, and other words, such as interrogatives. Thus the changing of a declaration to an interrogation is accomplished in Latin and English by some interrogative word or particle, or simply by the arrangement of the words. The relations to reality may be various. To begin with, the relation may be either declared or demanded (asked for). This gives declarative and interrogative sentences. The declared relation may, again, be of various degrees of correspondence. This gives-

Modes.-These may be tabulated as follows:

I.--Declarative modes.

I.-- The real mode, indicative,

2.-The Ideal modes :

a) imperative,

b) optative,

c) subjunctive.

II.--Interrogative mode. 
The term assertion is generally used in grammars as antithetical to interrogation (what we call assertion is generally included in predication). Assertion is not so used here, as the definitions indicate. Even a question is a mode of assertion, for it asserts that the sentence does not declare reality, but seeks for it. Hence it asserts the speaker's will in regard to the declaration of a thought by the hearer. The imperative mode asserts as well as any other, and is here classed under the declarative as one of the ideal modes. It asserts the will of the speaker. It is closely connected with the optative mode, and in most languages the difference between a will and a wish can be made infinitesimal. "May you be happy," and "be happy," both assert the will or desire of the speaker and nothing more. Imperative, optative, subjunctive, and other ideal modes as well as the indicative, are all spoken with the purpose of increasing the hearer's stock of knowledge, and therefore they declare something to him. The interrogative is used with the intention of increasing the speaker's knowledge, and uses declaration only as means to an end. It seems possible to divide even the interrogative into real and ideal modes. Compare Quid facimus? What are we doing? and Quid faciamus? What ought we to do? This distinction refers to the mode of the answer, however. Exclamatory sentences are nothing but declarative sentences expressed with unusual feeling.

Times.-Real space and ideal space are the same, and so are real and ideal time; but though thus located in real time and space even before or without assertion, a clause may not have its position defined in relation to the real now and here. There is, however, a difference in the relation of time and space to assertion. A clause is located in space even without being asserted, but located in time in reference to the actual now, only in and by assertion. This is proved by the fact that the finite verb is universally the time-word, and that the verb loses this power of denoting true time as soon as it loses its power of assertion. Participles and infinitives, according to all grammarians, denote only relative time, or time measured from the now of the chief verb, not from the actual now; that is, as we intend to prove, they do not ex- 
press time at all. Hence the time-relations as pure timerelations are expressed only in the assertion, while space relations are expressed in predication as well. Why this distinction between the two forms of the sense-world?

The now of time is more important than the here of space. What is here to-day may again be my here to-morrow, and also may not be. My here and your here may follow different laws and be different successions. But my now and your now follow the same laws and are identical successions; the procession of nows is as fixed as fate, and can not be changed by our will, because it is the very essence of change. A mile from here may be an insuperable disiance, or may be the merest trifle, as topography, steam, and electricity may decide. Distance north may be the same as distance south, so far as the moving of the here is concerned, or it may not be. Time is different in this respect. Motion backwards is totally impossible, motion forward is absolutely unavoidable. Hence the obstrusive importance of the now compared with the here. In time, we refer all to our actual now, but in space, we do not at all so frequently refer to our actual here. The imaginary world in which we generally locate the presentations of thought is emancipated from the bondage of the now; but in asserting a proposition it must be given "a local habitation and a name" in the real world, and then the relation to the now must also be given. And all this plainly follows from the fundamental antithesis between time and space. All the world has the same now, no two things can have the same here. When we say that two or more things are here, we are conscious that this is an inaccuracy, since where one thing is another can not be; but there is no inaccuracy in saying that all the world has the same now. And not only so, but everything has had all the nows of time; for we can not choose but think that all that exists in the now of to-day existed also in some form during all the nows of the past, and will exist during all the coming nows. This gives the now its immense superiority over the here, when reality is to be located. 
But it will be objected: do not adverbs and even prepositions and nouns denote time? The word now, so often used in this discussion, is an axample. Do we not say, "after rain, sunshine", and does not the preposition after denote succession in time? This is all true, but none of these words represents time as time; the adverbs represent time as a circumstance, and the prepositions symbolize time as a space relation, while substantives represent it as a thing. There is another class of words which express time as time, and these are the conjunctions, of which we have spoken. Besides, the property of state of the verb (the power of expressing an action as "perfect," actual, or potential) expresses a time-relation. But state is determined from the time of actualization of the event itself; the verb alone represents time-relations as measured from the actual now of the speaker.

As we have seen, nothing in the space-conceptions corresponds fully to the tense-time of the verb, as the location in space has no reference to the assertion. If the fact that tense-time belongs to assertion is disregarded, the function of the demonstratives corresponds in the space-categories to the tense-time of the verb in the time-categories, since the demonstratives locate in space from the speaker's here, just as tense-time locates in time from his now.

The pure time-determinations of assertion are, in the classical and Romance languages, three; in the Germanic two. When three, they are past, present and future; when two, past and present. Tense is not synonymous with asserted time; it is used as a name of the forms of the verb resulting not only from time, but from state and duration as well. Thus the imperfect, historical perfect, and pluperfect are all past tenses in Latin.

Both the present tense and the logical perfect tense are present in time. In English, however, tense and tense-time correspond; these are, present and past. No compound forms are admitted.

Construction.-Construction is of two kinds, union of elements on equal terms (predication), and union of elements 
when one is a determination (modifier) of the other, and therefore subordinate to it (determination).

\section{CHAPTER X.}

\section{Predication.}

What is asserted.-But what is to be asserted? This depends on the teleology of speech; language is used for the purpose of increasing the knowledge of the listener, and the question then becomes: In what form must new knowledge be presented to the mind? What would Friday wish to tell Robinson Crusoe? Not the rock, river, sun, sea, bird, palm, or hut. Those were present in the conscionsness of Crusoe as well as of Friday; they were uninteresting, because well known, old. The flight of the bird, the fall of the rock, the ripening of the fruit, the storm, the rain, and the sunrise, on the contrary, were of interest to both, because new and not yet known.

This psychological law of interest determines the very groundwork of the sentence. The event alone can be asserted, since it alone is new and an addition to knowledge, and hence is the only thing worth asserting. What is uneventful is not worth talking about; if absolutely nothing lappencel there would be absolutely nothing to say. We can not add things directly to our stock of knowledge. When things enter, they must come as events (existence). The event of birth adds the child to the conscionsness of the family; the event of introduction adds the stranger to our list of acquaintances. We can not assert a thing, but we can assert the existence of a thing, and existence is an event.

Subject and predicate.-Assertion demands an event; we can not assert without asserting an event. Here the psychology of event is of importance. We have seen that an event can not be perceived or imagined without including a thing in the sphere of attention. This must appear in language. 
The event is the predicate and the thing is the subject. The peculiarity of the event which is perhaps most striking is that it is thought of as having an individual existence, and yet an existence which is always united to an object, a thing. The motion and the thing moving are both one and two things. Neither the event nor the thing is the more important; both are of equal dignity and unite on equal terms.

Definitions of predication.-Predication means, consequently, the union on equal terms of a thing-presentation and an event-presentation in the hearer's world, or the union of a verb and its subject. It is to be noticed, that it is the nature of the verb that demands predication, not the nature of the subject.

The subject included in the verb.-As an explicit act of the mind, the above applies only to modern languages. The ancient classical languages implied the subject in the verb. Their verbs were propositions, and needed not to seek a subject, as they included the subject. This, again, shows the superior analysis of the moderns. The ancients did not abstract motion from thing moving or event from thing happening. A race low in intellectual development had better not require of the hearers of speech such a fine analysis as the separation of the flying bird into two components, the motion and the thing. So they said "Volat avis," it flies, the bird. Volat asserts not flying simply, but flying thing, and avis stands in apposition with the flying thing. Moveo does not assert motion simply, as the English move does, but asserts a moving ego. Most modern languages have some relic of this former arrangement. E.g., the Spanish tengo, I have. But few go so far; with the English, it remains as the person and number of the verb. The person and number of the verb are simply the fragments of former pronominal endings, and they are put to wholly new uses when they are employed as helps in matching the right verb with the right subject. In passing, we may note that there is an absolute distinction between predication and assertion. As we have just seen, there may be explicit asser- 
tion without explicit predication, and there may.also be predication without assertion, as we shall presently see.

The subject.-The subject is a thing and represents a portion of the auditor's known world. The so-called impersonal expressions, as "it rains", "es scheint mir", "mig synes," are not, as some grammarians suppose,* without a "logical subject." The drops of the rain are the thing-subject and the falling of the rain is the event-predicate. There may not always be a distinction explicit in consciousness, but implicitly at least both subject and predicate are present, at least as much as in any verb of Latin or Greek.

Since an event-presentation can not be imagined without a thing-presentation in which it resides, every imagined or perceived event requires as its subject some imagined or perceived thing. Therefore every word that represents what belongs to the category of event must have a subject. That is, all verbs and participials have subjects. As a subject may be used any word that expresses a thing; such are substantives and substantive participials. The subject is never put in an oblique case, because it is a subject. When, for example, the subject of the infinitive is in the accusative case, this is not because it is subject of an infinitive, but because the subject of the infinitive at the same time stands in an accusative relation to some other word of the proposition. "I saw him shoot." Here him is in the accusative, not because it is the subject of shoot, but because it is in the relation of direct object to saw. There are grave exceptions and anomalies to be explained in reference to this dogma, but they may be postponed till we come to objects.

Every participial has a subject, that is to say, every motion expressed by a participial is expressed as the motion of a thing moving, not as motion "in the abstract." The necessity of a subject for every participial is a psychological one. A true participial is the sign of a symbol that is imagined as an cvent in reference to every subordinate element. Now, an event can not be imagined without a thing moving. This moving thing is the subject. This subject

Paul's Principles of I.anguage, p. 120. 
may be explicitly stated, as in "dixit te imperator esse".; or it may be implicitly stated. Thus the substantive qualified is always the subject of adjective participials. "Alexander, conquering a world." Here the adjective nature of conquering has in Alexander the word it qualifies, while the verbal nature of the participial has the same word as its subject, $i$. $e$., it represents Alexander as joined to the event of conquering in the active voice. The substantive participials generally have the subject of the proposition as subject, but sometimes another word. As $e . g$. of a subject of the proposition as subject of the participial: "He lost my confidence by deceiving his clients." The subject of deceiving is implicitly expressed in he. "We attempted to dissuade him from storming the fort." The subject of dissuade is implied in we, the subject of the sentence, but the subject of storming is implied in him. It may, perhaps, be objected that this seems like a little too free construction, and that, possibly, the subject of participials when implied, is a creation of the author's fancy, and not recognized by any one else. But witness the following example: "He got a fortune by killing his uncle." What a wretch! Is not the subject of killing plain enough in this construction to send a man to state prison for life? "He got his fortune by the death of his uncle." This leaves the nephew without a stain on his name, for death, being a substantive, does not indicate a subject, that is, does not indicate who caused the dying. In the following, John appears as a good student: "By solving the problems in a special book, John managed to make perfect recitations." On the other hand: "By the solution of the problems in a special book; John managed to make perfect recitations." It is probable that this second John uses a key, for solutions does not point to Fohn as its subject, as solving does. And this depends ultimately on the difference between the psychological event, which happens when a substantive expressing an action is used, and that which takes place with the participial. As already explained, an event is imagined for the latter, and the event must have a subject; but when a substantive is used, the event is symbolized by some thing-presentation. Now, a thing can not 
have a subject, since it can not inhere in anything not itself, and as a consequence, no substantive points to any other word as its subject.

When the subject is neither implicitly nor explicitly expressed, it is understood as some person or thing in general. It may be noted that languages seem to avoid as much as possible making the subject of a participial nothing but the subject of the participial. Generally the word serves also in another office, even when explicitly expressed. But there are cases of the opposite kind. "Unam partem Gallos obtinere dictum est." Here Gallos is subject of obtinere and is dependent on nothing. But why, then, is Gallos in the accusative? This is an anomaly that will be discussed later. The two words, Gallos obtinere form together a complex which is the subject of est. Hence obtinere is at once in the relation of a predicate to Gallos and in that of a subject to est.

The predicate.- The predicate is an event and represents the addition from the sphere of the unknown to the hearer's knowledge. This is the place to discuss a fallacy that has caused much confusion in grammar. Even philosophic writers on grammar and logic speak of the predicate as an attribute of the subject.

Now an attribute is conceived as wholly dependent on its substance. In fact, it has no individual existence, but is wholly subordinate and secondary in reference to its substance. All this is not so with the predicate. The predicate is of equal rank with the subject. It is conceived as having an individual existence and as being only united to another, not as being nothing but a part of another. The attribute is lost in the substance; but when subject and predicate unite, they do not form either a qualified subject or a modified predicate, but a new creature that is neither the subject nor the predicate, but a union of both on equal terms. Take the typical sentence of all thought: Thing happens. Here the two words are of equal dignity. But if the predicate is degraded into an attribute wc have happening thing, in which the center of gravity is with thing.

How this fallacy of mistaking the predicate for an attribute came to be so common, is easily explained on psy- 
chological grounds. Our consciousness, in developing, always begins in the space-categories. We begin with the world as a collection of things, and though we soon are forced to recognize other categories, we constantly return to the primary category as to a native country and turn the spoils of our thought into its coffers by a "change of category." The tendency of human thought is to construe everything in the space-categories. Did we not even now express the universe by every-thing. The savage is said to personify every thought. But it is truer still that the universal characteristic of human thought is its thing-ifying of its content.* Half of philosophy is caution against undue thing-ification. An example of this unwarranted reduction to space is the mistaking of the predicate for an attribute. For this is a degradation of the predicate. Every proposition, every symbolic presentation of thought has two thought-forms-time and space, since it is a thing-event, but substance and attribute has only one form, space. Hence it is impossible to interpret thought in the forms of substance and attribute alone without reducing the temporal properties into spatial determinations; and this can not be done without loss, since time and space are not tautological repetitions of the same form. Hence the wealth of relations expressible by the two forms together is reduced and the underlying principle misinterpreted.

From the point of view of syntax, the verb is the fundamental word of the predicate, and from the point of view of dynamics, the event expressed by the verb is the fundamental presentation of the predicate. That is, all the other parts of the predicate are subordinate to the verb. The verb never determines the other parts of the predicate, but is always determined (modified) by them.

The "Copula".- It is, however, generally denied by grammarians that the verb to be (the substantive verb) is more than a bare "copula". The "predicate noun," or "predicate adjective," which follows, is supposed to be the predicate. It is argued that we are not conscious of asserting existence at

*If there are beings of a higher order who can use the time-form as basal, and thus eventify their knowledge, how rich must be their thought compared with ours! 
all. Then, again, if it is admitted that the verb has some excuse for being, it is maintained that still its "idea" must be of little importance, since such a small degree of attention is given to it. This is a radically wrong argument, since, on the contrary, the general tendency is to give less attention to the fundamentals of thought and the lion's share to the uttermost determinations. More attention is given to white than to elephant in the combination white elephant. Still the governing word is the latter. Few mortals, if told that a happy fate is in store for them, would center their attention on fate. It would be happy, happy, happy that would ring in their ears. For the wider and more universal a conception is, of the less particular interest is it. But, existence is the widest possible predicate, and hence the emptiest of all interest. Take the sentence: "The moon is our satellite." Is expresses here the basal conception of the predicate, but what care we to know that the moon exists? We knew that before, and even if we did not, simple existence "tells" us nothing about anything. Being is equal to non-being when undetermined. Hence we pay but an infinitesimal attention to $i s$, the assertion of existence. But this does not invalidate the assertion of existence nor defeat its purpose. Existence was asserted of the moon in order to have something to determine (or "modify") afterwards. Here is is determined by "our satellite," another name of the same existence. In "The moon is bright", the adjective bright determines the asserted existence by qualifying the existence. It is a bright existence. To say that in these examples no existence is asserted, is palpably false. The thought can not help extending the moon in time as well as in space. To assert a thought of the moon as only in space, would be a psychological impossibility. That we pay scant attention to the moon's duration is because it is so self-evident, so admitted. As is universally admitted, the verb to be does sometimes express existence, as in God is. Hence the law of parsimony is against every interpretation of the function of to be that is antagonistic to the one given above.

The union of subject and predicate.-Subject and predicate 
are not connected simply, they are united. In this respect, too, the "copulative verb" theory is faulty.* The verb to be is not a connective. Note the difference between "Cleveland is president", and "Cleveland and president." Not only does the latter group of words fail to assert anything, but the two presentations also remain two presentations. In the former case the two presentations become one. There is, consequently, not even a similarity between the verb, even the "copula", and the conjunction.

A subject and a predicate form together a predict. This is a new term, useful if not felicitous. If the predict is asserted, it becomes a proposition. Consequently, the predicts of verbs are always propositions; the predicts of participials never. A predict that is not asserted is treated in every instance as a single word, while propositions are combined according to laws of their own (temporal laws), and only exceptionally treated as simple words (after spatial laws). Thus, in this case, both propositions, and predicts that are not propositions, can be used as subjects.

Voice is a property that comes under predication. It expresses the relation of the verb to the subject. The English verb has but one voice, the active; the passive is supplied by the solitary passive participle. The Scandinavian languages are the only languages of the modern Germanic and Latin tongues that can boast of a true passive verb. Ex. Jag älskar, I love; jag älskas, I am loved.

Contrast of Predication and Assertion.-As our usage of the terms predication and assertion differs from the ordinary one, it may be well to reiterate the distinction. Predication is a union of an ideal event and thing of equal rank. Our knowledge is not increased by predication. It has to do only with the images that are used as symbols, not with what we call the "real" world in distinction from the ideal. Assertion gives the relation of the ideal world to the real. It increases the knowledge of the listener to speech. It is the appearance of the logical judgment in the sphere of language. Only what is asserted can be true or false.

*See Paul's Principles of Language. 


\section{CHAPTER XI.}

\section{Determination (or Modification).}

Division of determination.--Determination is of two kinds, determination of words, and determination of propositions as such. Temporal clauses, clauses of purpose, result, etc., are examples of the latter ; direct objects, "adjective and adverbial modifiers," of the former. Determination of words is again subdivided into three genera, internal, identitive, and external. When a presentation is determined by describing the presentation itself, that is, by giving its qualities and "differentia specifica," the determination is internal; when, on the other hand, the presentation is determined by other presentations, as when it is said that St. Paul is ten miles from Minneapolis, the determination is external ; when a word is determined by the use of another term signifying the same presentation, the determination is identitive. Apposition is an example of identitive determination.

Internal determination by words is of two kinds, attribution and modification.

Attribution is determination by adding an attribute to a thing. Adjectives and adjective participials determine by attribution. Substantives, substantive verbs, and the participials from substantive verbs can be determined by attribution. The gerund-grinder* of our younger days would have smiled approvingly on this exposition of attribution until he had come to substantive verbs. These are not admitted by traditional grammar as capable of being determined by attribution. An example will make plain the point in dispute. "Cyrus was powerful." The customary analysis is somewhat ambiguous. Powerful is said to be a "principal part" of the predicate, and again an "attribute of the subject" through the verb. The finite verb is rightly defined as the most important part of the predicate, yes, of the sentence; but when cases of this class are reached, the verb, as we have seen, is called a copula simply, and is supposed

\footnotetext{
${ }^{*}$ An expression from Carlyle.
} 
to have no higher value than the mathematical sign of equality. The explanation of the preceding chapter may be here utilized. The substantive verb, as well as every other verb, is the chief part of the predicate. It predicates and asserts existence. In the present example, was predicates and asserts existence of Cyrus. This is, however, the emptiest, because the most indeterminate of predicates. Hence the existence predicated of Cyrus is qualified by having an attribute added to it; that is, the existence asserted is determined by attribution. Therefore the sentence equals: Of Cyrus is predicated an existence determined by the attribute powerful. What in this theory can be questioned? That the "copula" verb can express existence all agree; example: "God is." The law of parsimony would require us to make no exception and introduce no new hypothesis so long as this hypothesis can explain the facts. But how can existence, which belongs to the time category, be determined by a space determination, by attribution?

The answer to this question is found in Ch. IV under "The double dimension of event." Events have space determinations as well as time determinations, because of the peculiar obtrusiveness of space. Only the substantive verbs, however, go the length of taking adjectives as determinations, since in existence the variation-element is less prominent than in motion (expressed by motion-verbs), and hence more attention can be given to the secondary form, space.

Modification is the process of determination by expressing the manner of that which is to be determined. Adverbs determine, and verbs, participials, adjectives, adverbs, and, perhaps, prepositions and conjunctions, are determined by modification.

Identification, or identitive determination is subdivided into apposition and detcrmination by a predicative.

Apposition is here given its usual meaning. The appositive gives another name to the same thing as the word it limits. It is called identification, because its meaning is identified with that of the determined word.

Determination by a predicative.--Again ive must disagree 
with the accepted doctrine. Traditional grammar has been prolix in inventing names and rules for the substantive that occurs in the predicate with the substantive verb. It is called a complement, either predicate, subjective, or attribute complement, a predicate nominative, a predicate noun, and the like. The view here maintained may be brought out by an example: "Sherman was our leader." Of the subject, Sherman, is predicated and asserted a past existence by was. The existence expressed by was is then determined by having another name given to it, namely, leader. Leader and was refer to the same existence, hence leader is said to determine was by identification. The predicative is nothing but a substantive (or the substantive participial) in apposition to a substantive verb, or to a participial from a substantive verb. It might, therefore, with propriety have been classed with apposition, but the great importance and peculiar use of the predicative seems to warrant a separation. Wherein they differ gramatically is shown by the following: Substantives and substantive participials can be determined by appositives; substantive verbs and participials from substantive verbs can be determined by predicatives. Substantives and substantive participials are used as appositives and predicatives.

\section{CHAPTER XII}

\section{Determination:-Objects.}

(CONTINUED.)

External determination, or location.-A presentation may be determined (modified) by having its location in space defined in reference to other objects. "Caesar crossed the Rubicon." Here crossed is located by Rubicon. "Carry the war into Africa." Carry is located by Africa. All presentations have to do with space, those of time as well as those of space. But all presentations do not possess space in such a stable manner that they can be used to determine the 
location of others. As a consequence, both event and thing can be determined by location, but only thing can be used to locate other presentations. Words (and presentations) used to determine others by location will here be called by the common name of object. Location, like internal determination, may be subdivided into two classes, determinations of thing and determinations of that which does not possess space in the absolute manner that thing does. As motion is the chief example, it may briefly be called determination of motion.

Object and case are not synonymous. Case (casus, a bending) refers to the form of the word. Thus we say, properly, that the Latin has a dative case, since it has a special form by which to express the relation of towards, but the English, lacking such a form, has no dative case. But it would be improper to claim that the English has no dative objects, as object refers to the use of the word as a determinator by location. Ex. "Give me the book." "His native island is dear to the Icelander." In these examples we have as good dative, or indirect, objects as any language can show, but we have no dative cases. Case belongs to morphology, objects to syntax.

Thing-determining objects.-These objects are expressed by the genitive case, and by objects with prepositions like of. The partitive genitive is the typical thing-object, as well as the typical thing-case. Hence thing-determining objects may be divided as follows: (I) the typical genitive object, (2) other genitive objects, expressing a relation and determination not fully genitive.

The genitive is used with adjectives in Latin, but it is not hard to prove that all these adjectives have a figurative meaning, i.e. symbolize as quality what would be symbolized more directly by some other category. Generally the direct category would be motion. Hence, often, that object which would have been some sort of accusative or dative object, if the adjective had been a verb, is put into the genitive. Ex. "Sapientia studet, sapientice studiosus." In both cases, the desire is supposed to be very intimately connected both with him who desires and with the object of desire; that is, 
it is thought as being a part of both. And the relation of the whole to the part is the relation of the genitive. This genitive we would classify under (2), since it is, after all, a violation of the category of quality to thus speak of it as a thing. Herein it does not strictly comply with the rules of the genitive. The genitive objects can be used with the same right to determine substantive verbs and their participials as to determine substantives. All the languages here investigated agree in this.

The genitive with verbs in Latin is simply a case of ellipsis, or of a cognate accusative in the verb. Ex. Reminisci virtutis. In full it would be: to remember (that which belongs to) virtue. We sometimes use the same symbolism in English; we remember (something) about a person, we think of our friends. The construction is here fully genitive, and it is the implied object in the verb that is determined by the genitive object. In Latin, we remember (a memory) of the thing, we enjoy (the interesting) of an affair. When the accusative and genitive are used, the same explanation holds good. "Milites necessitatis monet," he warned the soldiers (a warning) of the necessity. There is here a cognate accusative in the verb monet, which we have rendered by a warning; this is determined by the genitive necessitatis. The genitive with verbs in Latin may accordingly be ranked with genitive objects under (I).

The relation from, and other circumstantial relations, are somewhat connected with the relation of the whole to its parts. In ordinary experience, we are seldom forcibly reminded of the relation of a whole to its parts except through separation. This practical, close connection has been recognized by the Greek language, whose genitive case expresses both thing-determination (whole to part) and motion-determination (circumstantial relation as separation). Consequently, we must say, that the Greek genitive case is not always used for genitive objects, but sometimes for circumstantial objects. Some prepositions seem always to denote the relation of an object to a thing as of, von. Others seem to have received their meaning, like the Greek genitive case, without reference to our fundamental distinction. 
The motion-determining objects.-These may be classified as follows: (I) Accusative objects, $(a)$ the typical accusative, the direct object; $(b)$ other accusative objects; $(2)$ dative objects, $(a)$ the typical dative, the indirect object; $(b)$ other dative objects; (3) circumstantial objects, as ablative, locative, instrumental, and the like.

The accusative object represents that presentation in perception or imagination which terminates the motion of another. Accordingly, to begin with, it is thought of as that which receives the motion. The motion when determined by an object, is not thought of as destroyed but as transformed; and so this object is supposed to possess the motion as result. The direct object is, therefore, the truest accusative object. The cognate accusative is but a species of the direct object. This is too apparent to need illustration. There are other accusative objects which lack something in the full meaning of the accusative. Thus the Latin accusative of limit. "Romam venit." "Ad templum redit." English: "He came home." "He went to Africa." This accusative marks the termination of motion, and is in so far truly accusative; but it does not denote that which receives the motion as result; herein it fails in the full meaning of the accusative, and hence it comes under $(b)$ of the accusative objects. The medium through which a motion passes, terminates it gradually, and as physics proves and common sense believes, receives the motion as a result. A ball passing through the air, or a blow in the water, illustrates what is meant. Therefore, the medium of a motion may be considered as that which absorbs and terminates the motion. Latin: "Decem annos rexit," and also in English, "He ruled ten years." Here ten years is symbolized as the medium in

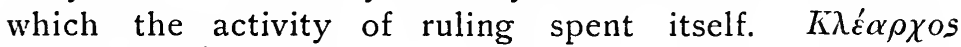

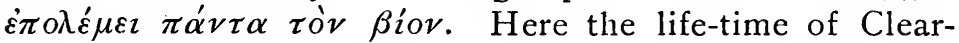
chus is considered to be the medium which absorbed and terminated the warring of Clearchus. When this accusative (in languages quoted here) is used without a preposition, it may generally be classed under $(a)$, but when a preposition occurs, generally under (b). This is not so in the Spanish, however, where a preposition sometimes "governs" the direct 
object of the verb. No preposition in these languages expresses the pure accusative relation, and the fact that a preposition is used indicates that the relation is not purely accusative. The accusative of specification and the adverbial accusative in Latin and Greek admit of similar explanations.

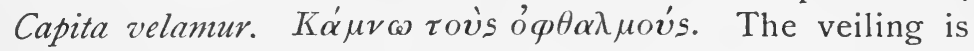
supposed to affect the head accusatively, likewise the laboring the eyes. Pure accusatives they are not, as there must be a change of symbolism in the sentence in order to make the relation accusative. Some of these accusatives can be best explained as linguistic make-shifts. Whoever first used them, felt it in a dim, ill-defined manner that the determination he wished to add, had a very close connection with the idea to be limited. So he symbolized the determination by the accusative object, as this is in some respects among objects the most intimate determination. The English "accusative case" after prepositions is only a chameleon's skin, which continually changes its colors of relation. In English it has come to be equivalent simply to a mark of dependence, and with a preposition may stand for any relation. The so-called accusatives without prepositions, which express time, distance, price, and the like, are no accusatives at all, neither cases nor objects. Ex. "It was a yard long, and cost us a shilling." There is no case-ending, and the relation is evidently circumstantial. But it is easy to see how the grammarians came to call it accusative. They first declined the English noun into three cases, making the accusative and the nominative alike. Then they were led to confuse the meaning of object and case, since else their accusative case of the noun would have meant nothing. They found certain nouns obviously in a dependent position but without prepositions, and with the form common to nominative and accusative. Nominative they could not be, as that form does not denote subordination; therefore they called them accusative.

The use of the accusative as the subject of the infinitive is explained in most cases by the fact that the subject stands in an accusative relation to some other word in the sentence. But when the infinitive with its subject forms the 
subject of the proposition, such an explanation is precluded. Te esse servum dicitur. Why is te in the accusative? Together with esse it forms the subject of the verb. This seems to be simply an anomaly, a mistake of the logic of language. Historically, it is probable that at first infinitives with their subjects were used in subordinate positions where the subject did stand in some accusative relation to a superordinate element, as, "dicit te esse servum." By analogy, (the mother of one-half of language) this case was retained when the subject stood in no such dependent relation; and instead of rectifying the error, it has been perpetuated, perhaps because we feel that the subject of an infinitive is not of the same dignity as the subject of a verb, and ought to . bear some badge of inferiority.

The dative object denotes that towards which a motion is tending, and is accordingly the object of direction, especially direction towards. The relation of the person who receives the less material effect of an action is generally symbolized by this object. The truest dative object is the so-called indirect object. The dative object offers few difficulties. In passing, it may be remarked that the dative forms used with substantive verbs (Tibi est pater. Est militi-

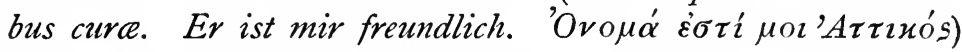
are datives of the $(a)$ class, but the dative use with adjectives, nouns, and adverbs are dative objects of the $(b)$ class

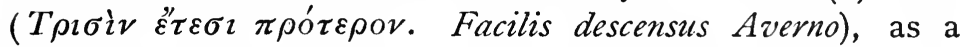
change in the symbolism of the governing word from rest to motion is necessary to make the dative intelligible.

It has already become apparent that objects might be divided and subdivided into an almost interminable number of classes. Thus, "other" dative objects, is but an excuse for performing no further subdivisions of the dative. Strictly speaking, every preposition is followed by an object peculiar to it, and therefore every preposition has a class of objects of its own. Yes, in some languages, as in Greek, certain prepositions have two or three cases of their own, as a dative and an accusative. But it would be impracticable to carry the division so far, invent names, and describe them all in an essay like this. Besides, the classes 
already treated are by far the most important, so it is no violation of symmetry to class all the remaining objects together as

Circumstantial objects.-Their relations are not so intimate as those of the accusative and dative. Such are the ablative proper (from), the instrumental (a figurative use of the relation $b y$, neighborhood), the locative, and several others.

Double objects, etc. - There are certain dogmas about double objects, "objective complements," and the like, which may well come up for consideration here. The two accusatives, one of the person and one of the thing, make in Latin an innocent construction. Philosophiam vetustam me docuit. In English, we would think philosophy as the direct object and $m e$ as the indirect, since we have no special dative case; but the Romans thought both as accusative objects, as the caseendings show. But they and we get into trouble in turning the expression from the active into the passive, for but one of the two accusatives can be used as subject; the other is left as accusative object. The person is made subject and the thing is left in the accusative. There, however, we have the anomaly of an accusative after a passive verb. This shows the necessity of a double symbolism, and consequently, that this object is not a pure accusative, but comes under $(b)$. The other case of two accusatives in Latin, that of the same person or thing, occurs in all languages here noticed as the "predicate objective," or "objective predicate complement." This has been made a fearful and wonderful thing by the parsing-master. Let us take the most typical. "They made him captain." The grammars tell us that captain is an "essential part" of the predicate, and him is direct object. This analysis is too indefinite; besides it may or may not be interpreted so as to be true. Here there is plainly an ellipsis; and we shall do well to take another example first, which is free from this difficulty. "They forced him to become captain." Subj., they; pred., forced; direct object, the predict him to become; predicative of become, captain. Nothing is unwarranted in this explanation. That an infinitive with the accusative may be used as direct object must be admitted. 'Likewise, that an infini- 
tive can take a predicative. As the subject of the infinitive is in the accusative, it follows that the predicative should be so too. Now the analysis of our first problem is self-evident. Subj., they; pred., made; direct object, him to be, be being the infinitive of a substantive verb understood after him. Predicative of the infinitive $b e$ is captain. Surely we have as good right to understand an infinitive here as, say, a subject for an imperative. The absence of the form does not prove the absence of the distinction. Besides, the infinitive is not absent except in a few, stereotyped, much worn, idiomatic expressions, which, however, recur so often that, though elliptical, they have been taken for normal and complete expressions by uncritical grammarians.

Prepositions and objects. - We can not leave the object without protesting against the very common formula in parsing: "object, or substantive, governed by a preposition." This expression has a false philosophy behind it, as it makes the relation between the verb and its object the same as between the substantive and the preposition. Nothing could be further from the truth. The preposition is not the superordinated element in relation to the object, as the verb is; nor is the preposition determined by the object, as the governing word always is. The preposition neither determines nor is determined by the object, but shows simply in what manner the superordinate word is determined by the object in question. The better grammars of to-day have noted and rectified the error. But the average parsingmaster has not. But we must forgive the parsing-master. His view of grammar is as "practical" as it is uninspiring. Grammar is to him the science-no, the art, that teaches the schoolboy where to place his endings in his Latin compositions. So he is always on the lookout for a cue, never for a principle; but he can not prevent his language from implying an unconscious philosophy. He has found it a never failing rule that the substantive after per is in the accusative, and as a cue to one who attempts to write a language after rules and not after instinct, this is of considerable value; but now, he concludes that in some way per is the cause of the accusative after it, that it is per that makes the following 
word accusative. This is wrong. The cause of the accusative ending is the same as that of the preposition, namely, the limiting relation of the object to the word determined. To say that the preposition governs the object is like saying that the violets of spring govern the roses of summer, just because roses come after violets.

\section{CHAPTER XIII.}

\section{Determination.}

(CONCLUDED).

Determination by Propositions.-We have now arrived at the second and last grand division of determination ("modification"). The element used as a determination is no longer a word, or a phrase used as a word, but a whole proposition. When predicates and propositions are used as subjects, objects, predicatives, and the like, or with prepositions, they are used as if they were simply words. The case is different when the propositions condescend to be used as determinations in their own right and name, so to speak. Then other laws are followed and other principles obtained. Here it is well to bear in mind the following principle. Within the proposition there is no true time-relation. All relations are there symbolized as space-relations. The proposition as a whole is then located in time by the verb. But between different propositions there are sometimes true relations of time.

The first distinction is between proposition determining word (relative clauses), and proposition determining proposition (conjunctive clauses).

Propositions determining words, or the relative clauses.The relative word, if a substantive, stands in apposition to some word in the chief clause, and, at the same time, fulfills some office in the dependent clause. If an adjective, it is an 
attribute in both clauses; if an adverb, a modifier in both. Hence the essential thing is that the two clauses should possess a word in common, and that this should be a relative word. The whole force of a dependent clause then becomes a determination of the word in the chief clause which is determined by the relative.

Propositions determining proposition.-(I) Mutual determination.-The co-ordinate conjunctions, as truly as any other, express a succession of presentation-complexes. These complexes, now elevated to the rank of propositions by the verb, sustain some relation to one another, and thereby they mutually determine one another; this relation is expressed by the co-ordinating conjunctions. Hence the relation of co-ordinate propositions to one another is that of mutual determination.

(2) Determination by subordinate propositions.--Our thoughts must, of course, be thought in succession. Thus, if we think of the fall of the Roman empire and the causes of it, the decline of Roman virtue, and the influx of Barbarians, we must think these three thoughts in succession. And, as far as results are concerned, it matters little in what order they come in the succession. But this is not a succession of importance for symbolism. The mind places its symbols in a certain succession at will, and the order in which the symbols are suggested to the mind has nothing to do with the order in symbolism. What is last thought of, may well be placed first. Thus, in the example above, the causes, influx of barbarians and decline of virtue, are invariably thought in the symbol as preceding the result, the fall of the empire. It is of no importance which was first thought of, cause or effect, cause is still always placed in the symbol as going before effect. The mind accordingly places the symbols in any succession it pleases; but succession is an exceedingly simple relation, being, nothing but a faultless procession. The determining and the determined propositions are both members in the same line, and must be either before or after. Still, by this simplest of relations in the sense-world, men symbolize the profoundest relations in the conceptworld. Not only so, but the mind knows these highest re- 
lations, such as cause and effect, plan and end, only by time-relation in the sense-world. The nearest we can come to perceiving cause and effect, is to find them both together, or in immediate succession; and co-existence will in these cases always be interpreted to be in reality a case of succession, as we cannot help thinking that the cause of the beginning of the effect, must have been prior to the beginning, though the cause of the latter part of the effect may be subsequent or co-existing with the beginning of the effect. Succession is not cause and effect, but only through succession do we know cause and effect. And so with the other relations. It must, however, have been hard to invent symbols of the expression for these relations out of so meager material. Accordingly, at first, they were not expressed, but left to be inferred. So it happened that the Latins generally said: "I fear. May he not hurt you!" when they meant, I fear lest he may hurt you. But the forefathers of the English would say: "I fear. He may perhaps hurt you." When at last, both people invented symbols for the unexpressed relation, it happened that there was a not in the Latin which did not have its counterpart in the English, which has caused untold trouble for generations of English boys.

Well-defined subdivisions of this class of determination, from the point of view of general grammar, seem impossible.

The expression "double symbolism" occurs quite frequently in this chapter, but possibly its meaning, from the psychological side, has not been made clear. Ordinarily the symbol of thought, which is an image or part of an image, belongs to one category of symbols, and to one only, throughout the time it is employed. But sometimes the image changes from one category to another, and still the thinker considers it the same symbol. This, which is the exception with other words, is the fundamental law of participials. What occurs as a rule with participials, may happen as an exception with other words. When, for example, a substantive is determined by an object that belongs to a class which implies motion in the determined word, this 
must, when not explicable as ellipsis, be explained as a case of double symbolism. In relation to that object the substantive symbol must be thought as a motion. Now, it may be objected, that a thing-presentation can not be changed to a motion-presentation, and that when we think so, we are mistaken; what we take for a change is really a substitution, the presentation is no longer the same. To which may be replied that, strictly speaking, a presentation has no identity to lose. In what sense is the image I make in my mind, of the moon, identical with the image I made a year ago of said luminary? Or, if I steadily keep an image of the moon before the mind for ten consecutive seconds, is the image at the tenth second the same in material as the image in the first second? The question is unanswerable because absurd. The only reason why a presentation is called the same in two consecutive seconds of time, is because we use it as a symbol for the same meaning. 
Outline of Syntax:-

A.-Assertion.

I.-Mode.

I.-interrogative mode.

2.- declarative modes,

a) the real mode, indicative,

b) ideal modes, (aa) subjunctive,

(bb) optative, (cc) imperative.

II.-Tense-time.

I.--future (not in English),

2.-present,

3.- past.

B.-Construction.

I.-Predication. To predication belong

I.-voice,

2.-person,

3.-number.

II.-Determination,

I.- of words.

(a) internal determination, (aa) attribution (adjectives, etc.), (bb) modification (adverbs, etc.), 
b) identitive determination, (aa) apposition,

(bb) determination by predicative,

c) external determination,

$(a a)$ of thing by thing,

(bb) of "motion" by thing,

a) accusative objects,

aa) direct object,

$b b)$ other accusative objects,

b) dative objects,

$a a)$ indirect objects,

bb) other dative objects,

c) circumstantial objects,

2.- - of propositions,

a) proposition determining word, or relative clauses.

b) proposition determining proposition, or conjunctive clauses,

(aa) mutual determination, or co-ordinate clauses.

(bb) determination by subordinate propositions, or "dependent" clauses. 


\section{PART IV.}

Morphology, or The Parts of Speech.

CHAPTER XIV.

\section{Prolegomena to Morphology.}

Statics treats of the nature of symbolic presentations, morphology of the consequent classes and properties of the words in language. We shall first consider some principles of interpretation.

What is a word? -Up to this point we have had no occasion to refer to speech directly, except in Part III, which is a composite of syntax and the dynamics of symbols. If all treatment of syntax had been deferred until after morphology, this chapter would have been absolutely the first place where the problem of this thesis dealt with language directly. The preceding chapters would have been solely a treatise on the symbolism of thought.

The question, what is a word, is generally decided for us by the compositor and the spelling-book, but it would be rash to ascribe infallibility to either. Besides, written language alone separates words into distinct objects, orally we speakbyclausesinthismanner, as also the ancients wrote. Since, accordingly, the spatial and temporal separation of words is artificial, the question is pertinent, Are words natural units of speech at all? To answer this question, let 
us ask another: Whether it be a natural or an artificial unit, what is a word? "The sign of an idea," is the English reply: but since "idea" may mean almost anything, this is not very definite. The following substitute is more definite: Words are the signs of symbolic presentations. Hence the unit of language as the system of signs of presentations, is the word. Now, it is wholly arbitrary what we are to take as the unit of a presentation. Even a triangle consists of parts, and these again of smaller parts. Hence in the presentation as such we can not find the unit. The unit must consequently lie with the word itself as a sign; and the definition of one word becomes: One word is a sound complex or character-complex that can not be further reduced or simplified without losing or changing its character as a presentation-sign. Let us, therefore, subdivide language and see how far we can continue the subdivision before the nature of language as a sign-system is destroyed. The unit thus arrived at is the word. Take, for example, the expression, "silvery clouds." Interposing a word, we have, "silvery, fleecy clouds." We notice that both "silvery" and "clouds" retain their significance. Hence, we have here at least two words. But "silvery" may perhaps be two words. "Sil, fleecy, very clouds." Here we notice that "silvery" has lost its meaning by the division. Hence "silvery" is the unit, and is but one word. Generally, the fact that the ordinary writer separates the words, shows that in the consciousness of the majority each word as separately written, stands as an integral sign. Sometimes, however, we should be deceived by following this rule. Thus the infinitive with "to" is one, not two words; "to do," for example, is treated as one word, and it is not correct to introduce any word between the "to" and the infinitive; the "to" has in this case no meaning as separated from the infinitive. To be sure, it might be mistaken for the preposition "to," but a moment's thought on the subject will show that it has here no prepositional force whatever. It is only the sign of the infinitive.

It seems warranted, therefore, to establish the following principle, the complement of the former: Any group of 
sounds that, without the addition of other sounds, has a meaning, or that does not require any particular sound or group of sounds either before or after it to make sense in discourse, is a word. Thus is, can, has are words, not parts of words, as the compound-verb theory would have us believe. As long as a group of sounds can preserve its individuality as a word, and consequently can be placed in different groupings without losing its force, we must attribute an individual signification to such a group and treat it as a word-unit. It is incumbent on the grammarian to determine what this signification is. All "compound" verbs, etc., are consequently cases of incomplete grammatical analysis.

The grammarian lumps "have been taken" or "capti sumus" together, and calls them one word, thus treacherously getting out of his bounden duty to explain the relations that subsist between "have" and "been," "been" and "taken." To treat a whole phrase as one word is evidently no explanation either of the phrase or of the words that compose it. The grammarian's duty is to explain all the functions and relations of words. And he has not performed this duty by simply explaining the historical route by which the word has descended from antiquity to us. To say, for example, that once, long ago, the three words have been taken had each a signification, but that this is no longer the case because the expression is "petrified," is a false pleading. If this were a truly petrified expression, in which each single word had no sense, but only the whole combination, it would plainly be impossible to insert any words between have and been, been and taken, without destroying the meaning. But we can say, have never been successfully taken, and still the words preserve their individuality. Hence we have the principle: Two or more words must never be taken for one.

The existence of a word form in a language is sure evidence of the existence of a corresponding thought form; but the absence of the word form does not necessarily mean the absence of the thought form. In other words, we must often "understand" and "supply" links in the chain of the sentence. Thus, though no form of the verb, nor any special 
word denotes the subject in an imperative sentence, the subject is yet rightly understood. Also the fact that no dative case-form is found in English does not prove that there are no dative objects.

To know and to know that we know are not the same. "Ego is conscious of A," is not equal to "Ego is conscious of A+ego." So little attention may, also, be paid to a fact of consciousness that it disappears from memory almost immediately. Thus I may at this second be infinitesimally conscious of a certain stroke of the pen, but because I pay so very little attention to this movement, I forget it the next moment. (Hereby we do not intend to deny the totally unconscious character of some habitual movements.) That I should forget such a movement is only natural. Memory is always weaker than the percept remembered. If now, this was barely able to keep itself above the threshold of consciousness, it stands to reason that its memory will inevitably sink below the threshold at once. Consequently the easy and popular argument, "we are not conscious of having such an idea," is worthless in its usual form.

The center of interest is not always on what is psychologically and grammatically the word highest in rank. Thus in the sentence, "He found a gold coin," gold is probably the word that interests speaker and hearer most, and that consequently gets the lion's share of the attention. But grammatically the words he found are of most importance. To these words, all the others have the relation of determinations only. The perfect distinction of the emphasis of interest from the rank of words and presentations in the dynamics of thought is so apparent that it is surprising that any one was ever misled by it. Yet the "copula" theory testifies otherwise. In fact, however, the very opposite principle may be deduced: The vividness of a presentation in consciousness is generally in inverse ratio to its rank in the sentence.

Teleological economy.-The presentation-complex by which the hearer chooses to symbolize his thought after he has grasped the meaning of the speaker is seldom the same as the one by means of which he understands the speaker, the 
one which is built up piece by piece in the auditor's mind while listening to speech. The former is generally the simpler. Thus when the speaker says, "He has great gifts," the auditor must imagine "he" as possessing something, but at the end of the sentence he is at liberty to exchange this indirect symbol for a simpler, perhaps one that might be represented by "A talented man." This latter, or teleologic, image absorbs all the attention, and the circumlocutory way by which we arrived at it is forgotten. This tendency to withdraw the most of attention from the images raised by the speaker as soon as they are understood, and to construct a simpler image that represents in a preferable way the "sum and substance" of what is said, may be called teleological economy. The symbol constructed by the speaker in the mind of the auditor may be called the primary symbol of thought; the symbol by which the listener chooses to represent the thought to himself afterwards may be called the secondary symbol.

\section{CHAPTER XV.}

Words Belonging to the Categories of Space.

Substantives. - The signs of the first category, things, constitute the first class of words, substantives. A substantive always stands for a space occupying presentation, but this presentation may symbolize anything. Thus the word "relation," when used in a sentence, is represented for the mind by some counter, very often the printed form of the word, which may then be located in or between other things. It was by mistaking this symbol of relation for actual relation that the Eleatics got one of their famous proofs of the impossibility of plurality. A and B must be separated by something if they are to be different things. Let us call that which separates $C$. But then $A$ and $C$ must again be separated by $\mathrm{D}$ in order not to be identical, and so on ad infinitum, that is, it is absurd to believe in plurality. This is 
equivalent to: $\mathrm{A}$ and $\mathrm{B}$ must be separated by a relation; if a relation is considered a thing, it must occupy space, and itself stand in some relation to $\mathrm{A}$; this new relation is considered as another thing, and so on. The symbol has been mistaken for the meaning. The very nature of a relation is not to occupy space, but to exist in the higher unity of the two objects, but when thinking of a relation we must symbolize it by some spatial counter, by some symbol of sense. So what the Eleatics proved is the inadequacy of the category of thing to express the full import of actuality, and not the impossibility of motion and plurality. In language we have nothing directly to do with the meaning of thought, but only with its symbol. Language is symbol-construction. Hence, all substantives are treated as if they verily stood for space-objects, as they do in the sphere of symbols.

Nouns and pronouns.-Substantives are divided into nouns and pronouns. Here it becomes necessary to break at once with popular grammar, which lacks nothing so much as logical classification. The difference between quality and thing is considered great enough to warrant the establishment of different parts of speech, nouns and adjectives; then in the next breath adjective pronouns and substantive pronouns are classed together as pronouns. Now, if the difference between quality and thing is the ground of division, there certainly is as great difference between this and $m e$, hic and me, as between blue and sky; and one logical way of classifying these words would be to make four parts of speech, namely, nouns, adjectives, substantive pronouns, and adjective pronouns. But then it would also be necessary to separate adverbs into two classes, adverbs and abverbial pronouns (relative, interrogative, and demonstrative adverbs); for if the general and substitutive force of the pronouns is sufficient as a basis for separate classification in words like this and he, the same property in an adverb like then or where ought to receive an equal honor. But this property of being general signs is not of so great and distinctive importance in the sentence as to warrant the establishment of separate parts of speech. Hence we shall class nouns 
and substantive pronouns together as substantives, and use "nouns" and "pronouns" as subdivisions of substantives. It follows that in this system, pronoun must always stand for "substantive pronoun."

Save the division into common and proper nouns, there is no classification of nouns of great importance from the standpoint of symbolism. The subdivisions of pronouns are very interesting; they are
a) representative,
b) relative,
c) interrogative.

Under representative, we include "personal," "reflexive," and such "indefinites" as are of a substantive nature, as man and etwas in German, and on in French; the classification becomes, then, very simple and we hope, rational. Pronouns that simply represent a thing-presentation by a general name, are called representative pronouns. The relative is a pronoun which stands in apposition with its antecedent in the chief clause, and therefore determines it by identification (see Syntax), and in addition is the sign of a thing - presentation in the dependent clause. In English we have one truly substantive relative, who; the other relatives are adjectives. Latin has no substantive relative; Greek, one; German, two, wer and was. The interrogative pronouns are "relatives in search of an antecedent." Ex. English, who; Latin, quis (not qui, which is an adjective). The demonstratives, and generally the indefinites, are by their very meaning necessarily adjectives. The criterion to apply is to attempt to supply a substantive after the pronoun, and notice whether it consents to the position of an adjective. (See Principles of Interpretation at the beginning of this chapter.)

Number is the fundamental property of the substantive, since it is the fundamental of thing. This property is expressed directly by "number" of substantive and, with "change of category," by numeral adjectives.

Adjectives.-The category of quality has the adjective as its sign Accordingly, every adjective denotes a quality of a space-occupying presentation, as a taste, smell, color, form, location, or number, (thought of as quality). As a symbol 
it may very well stand for that which is not at all a quality of a sensible object. Adjectives are of two kinds:

I.-Special, (green, quick),

2.-General, (adjective pronouns),

a) representative, (some, aliqui),

b) demonstrative,

c) relative,

d) interrogative,

e) possessive.

The representative adjectives are the signs of some very general attributes, as that of being an object (some), of being the neuter gender $(\tau \imath)$, and the like. The rest of the general adjectives represent the space-position of the presentation as a quality, the demonstratives simply for the purpose of identification, the relatives to add a dependent clause, the interrogative to express a question. The definite article is the weakest, because the most common of the demonstratives. This is so self-evident that we shall not attempt a needless demonstration.

Expressions for space-relations are demonstratives, prepositions, and "case" of substantives. The space-determination of demonstratives corresponds to the time-determination of tense-time, since demonstratives determine from the here of the speaker, and tense from his now. Case corresponds to "state" of verbs, and prepositions corresponds to conjunctions.

When the reason for expressing the relation between two presentations is to locate the one by the other, the relation is expressed by prepositions and cases. These locating relations are of two classes:

I. Relation of thing limiting thing.

2. Relation of thing limiting motion.

The former relation is expressed by the genitive case and prepositions like of, von, and $d e$. This relation of thing to thing expressed by the genitive is the relation of the rest of the whole to a part. The partitive genitive is a typical example; certain uses of the genitive are elliptical or in some measure figurative. Ex. Magnum mumerum militum. Here militum expresses the whole and numerum the part, and the 
case-ending $u m$ expresses the relation of this whole to the

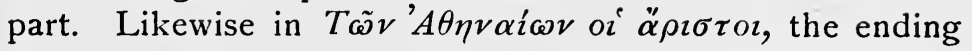
$\omega v$ expresses the relation of the whole, to-wit, Athenians, to the part, the noblest. "Plato's Dialogues." Here Plato is supposed originally to consist, not only of his personality, but also of that which belongs to him; hence his dialogues are also a part of Plato, and the 's represents the relation of the whole to the part. Possession, a rather figurative use of the case, has practically monopolized what little is left of the only oblique case of nouns in the English language. It is well to observe that through this whole discussion the spatial implications of the language used, must be taken quite licerally, and not figuratively. Every preposition, as well as every case, expresses, in every instance, a relation that in the psychological event in the presentation-world which serves as a symbol, is always a space-relation. On this symbol, however, we generally waste so little consciousness that we scarcely remember it, since we let the symbol at once lead us to its meaning.

The Latin case-scheme may be exhibited as follows:*

A. Thing to thing.

I. Genitive-whole to part.

B. Thing to motion.

I. Dative-direction towards.

2. Ablative proper-direction from.

3. Locative and instrumental ablative-neighborhood.

4. Accusative-limit of motion, that which receives the motion.

The Latin language is more logical in this respect than the Greek. The Greek scheme is the following:

I. Genitive-relation of thing to motion or thing-separation, whole to part.

2. Dative-neighborhood.

3. Accusative-limit.

*Prof. J. S. Clark, of the University of Minnesota, uses a very simple and suggestive diagram to represent the relations expressed by the dative, ablative, and accusative cases in Latin. The dative, and in some cases the ablative, are represented by a point, and the accusative by a line. "In urbe vixit." No motion, rest in, hence a point. "In urbem venit." Motion, represented by a line. "Anno primo post urbem conditam, hostes, etc." Here anno primo is the point in time at which something happened. "Unum annum regnavit." Unum annum is the stretch of time during which the reign took place, Hence a line. 
The German language is in this respect very similar to the Greek. The English and Swedish scheme is as follows:

A. Thing to thing.

I. Genitive-possession.

B. Thing to motion (in pronouns only).

I. Accusative-limit of motion.

As the French, Spanish, and Italian have no cases, save some remnants in the pronouns, further analysis is unnecessary.

Prepositions do not govern cases. The case-ending is not caused by the preposition. Both are expressions of the same relation, and hence essentially a tautology. In some cases, the endings are simply useless survivals, as the preposition amply indicates the relation to be expressed. Sometimes the case-ending may be of use as indicating of which word the preposition expresses the relation. This has been wrongly considered by the average school grammars, as the only use of "cases governed by prepositions." Languages of such finished symmetry as the Greek have avoided tautology in most instances by dividing up the work of signifying the relation, between the case and the

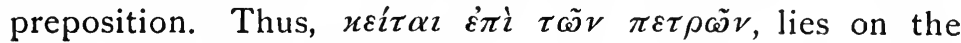
rocks, $\pi \dot{i} \pi \tau \varepsilon \imath \dot{\varepsilon} \pi \dot{\imath} \tau \dot{\alpha} s \pi \dot{\varepsilon} \tau \rho \alpha s$, falls on the rocks. 'Exí means, in both cases, on, but with the genitive rest on, and with the accusative motion unto.

Prepositions in modern languages.-The representation of space relations by prepositions instead of by case-endings marks a great advance in the logic of language. It introduces the epoch of thought when man rose from the category of thing to that of relation. To invent, use, and understand a case-ending it is only necessary to apprehend that a thing is in a different condition when receiving the effects of a motion (acc.) than when not so doing (nom.), when approached (dat.) than when departed from (gen. or $\mathrm{abl}$ ); it is not necessary to abstract from the objects entirely, and consider the relation in itself. That is, it is unnecessary for apprehending a case-form to distinguish a relation and the thing related. But this was exactly what had to be done before prepositions could enter language. They could 
never sustain their individuality until the hearer of speech could think a relation as a relation. When the first preposition was uttered, man had learned to abstract position from thing. Therefore, the English language is a far more developed tongue than the Latin, which never quite knew what to do with its few prepositions. Do we then mean to say that the great Roman thinkers are surpassed by the men in an English workshop? Far from it! Every system of symbolism must be suited to the average listener, not to the exceptional thinker. Then it must never be forgotten that languages are already old heirlooms, ancient instruments, when their best thoughts are expressed. Not the age of Cicero, but the age of the Twelve Tables drew the outlines of Latin. Chaucer, not Shakespeare, had a hand in making the essentials of English-yes, the great fundamenta go much farther back, to the dark, dank forests of Germany. Accordingly what we assert is this: that the Latin language is a more puerile language, more suited for the world's intellect before its beard was grown, than the English. And this the Latin is, because at its formative period the average Roman listener was less intellectually advanced than the Anglo-Saxon listener to English at its formative period. Hence, Latin would make an excellent nursery language, and would, doubtless, be more speedily learned by infants than English.

Prepositions are not only superior as standing for more advanced thinking, but also because they make possible greater exactness of speech. Half a dozen case-forms can not possibly express as many and as finely differentiated relations as the numerous prepositions of English and other modern languages. Prepositions can be invented when thing and position are differentiated; prepositions must be invented when recognized relations have so multiplied as to exceed the resources of the case scheme.

From the standpoint of rhetoric, however, the substitution of prepositions for case-endings is not an unmixed good. There is a directness and force about the old expressions which seem somehow to be dissipated when language becomes extremely analytic. 
Analysis of the Substantive.

A.- It is the sign of a thing. Therefore all that follows from being the sign of that which occupies space may be attributed to the substantive.

1.-number (discretion in space),

a) singular, b) plural,

2.-case (relation in spuce),

a) nominative, $b$ ) genitive, $c$ ) accusative,

3.- person,

a) first, b) second, c) third,

4.--gender,

a) masculine, b) feminine, c) neuter.

Classification of Words belonging to Space-Presentations.

I. Substantives,

1.- nouns, or special substantives,

a) common,

b) proper,

2.- pronouns, or general substantives,

a) representative, he, it,

b) relative,

c) interrogative.

II. Adjectives,

I.-special, red, bold,

2.--general, or pronominal,

a) representative, some, none,

b) demonstrative,

c) relative,

d) interrogative,

e) possessive,

III. Prepositions.

\section{CHAPTER XVI.}

Words Belonging to the Categories of Time.

Verb Classes.-The verb expresses the event. Verbs are of two kinds, substantive verbs, or existence-verbs, and mo. tion-verbs. The two classes can not be separated by any 
definite line, and several seem to be used sometimes as substantive verbs and sometimes as motion-verbs. Substantive verbs can be determined by all classes of subordinate elements found in grammar except direct object. Hence in addition to other verbs, they may be determined by predicatives, genitives, and adjectives.

The verb; properties.-From its fundamental nature as sign of that which continues, the verb has two properties, duration and state. These have been quite fully discussed under the categories, and in order to be understood, much of what properly belongs here, was inserted there. The verb has two "durations," aorist and progressive, and three "states," potential, actual, and perfect.

The term "aorist" is taken in honor of the Greek tense of that name; but the term "imperfect," could not be adopted, as that would have implied an antithesis to the perfect tenses. Here the nomenclature of grammar is atrocious. The antithetical tenses in Greek are not perfect and imperfect, but aorist and imperfect in reference to duration, present and perfect in reference to state. Thus, "zh $\lambda v o v$, I was loosing and $\varepsilon^{\prime} \lambda v \sigma \alpha$, I loosed, are antithetical, since one represents the action as continuing or being reiterated for some time, while the other expresses nothing about duration. Again, $\lambda v^{\prime} \omega$, I loose, and $\lambda \dot{\varepsilon} \lambda v \kappa \alpha$ I have loosed, are antithetical, one representing a present action, the other a present result of some action. In Latin the contrast is between imperfect and historical perfect on the one hand, and between present and logical perfect on the other. Cum transiebant Rhenum, Ceasar, etc. While they were crossing, progressive; Transierunt Rhenum, they crossed the Rhine, aorist. This shows one contrast, the other is shown in the following: Transeunt, they cross, an actuality. Transierunt (when taken as truly perfect,) they have crossed, a result. In English grammar confusion is even worse confounded. If there is anything that the English so-called imperfect is not, it is imperfect. It corresponds to the Greek aorist, and the Latin historical perfect. The Latin has but one form for the perfect and aorist, and this has unfortunately been named perfect, though it is used in the indicative more than 
nine times as an aorist, for once as a perfect. In the derivative languages, French and Spanish, it has produced the past definite, which is an aorist tense.

All "finite" English verbs are aorist in nature, and so is the infinitive and the passive participle. The participle in -ing is, however, progressive in nature. The Germanic languages, in general, have no progressive form for the true verb, while the Romance languages and modern Greek have such for the past tenses (the imperfect of these languages). In English the perfect state is expressed by the perfect participle only, and the progressive duration by the so-called "present" participle only. All English verbs are aorist, since the participles are not classed with the verbs.

$V e r b s$, predication-power.-In order to fulfill its purpose in the sentence, the event-word must be endowed with two other great classes of properties. One is predication-power, or power to demand a subject and unite with it. Under predication comes voice, or the manner in which it unites with the subject. No complete English verb has the passive voice. Only the perfect participle is passive. Person and number are also properties of the verb that belong to it only because of its relation to the subject.

Assertion. - This is the most important of the powers of the verb. Since infinitives and participles do not share this property, they are not here classed as verbs. Mode and tense-time depend on assertion. The English has only two tenses and two tense-times, the past and the present. The French has four tenses, future, present, aorist past, and progressive past, and three tense-times, the past, present, and future. The Greek has seven tenses, present, "imperfect" (progressive past), aorist, perfect, pluperfect, future perfect, and future; but only three tense-times, present, past, and future.

Adverb.-Variation is expressed by the adverb. Adverbs are classified as follows:

I.-Special, quickly.

2.-General ;

a) demonstrative, then, there;

b) relative, when, where;

c) interrogative, when, where. 
Conjunctions.-The category of succession is expressed by the conjunctions. They are of two classes, co-ordinating and subordinating.

Inflection of the English Verb.-

Indicative.

Present.

Sing.

Ist. P. $a m$

2nd. P. art, are, 3rd. P. is,<smiles>C1CCCCC1</smiles>

Plur.

are

“

6
Past.

Sing.

Plur.

were

“

"6

Subjunctive.

be.

were.

Imperative.

be.

The rest of the verbal paradigm in English is grammatical superstition.

Classification of Latin Tenses in the Indicative mode.-

I. Future,

II. Present,

$$
\begin{array}{ll}
\text { I. - actual } & \text { FUtURe, } \\
\text { 2.- perfect (result) } & \text { FUtURE Perfect, }
\end{array}
$$

I.--actual,

Present,

2.- perfect,

Logical Perfect,

III. Past,

1.- actual,
a) aorist,
b) progressive,
2.-perfect,
Historical Perfect,
IMPERFECT,
Pluperfect.

Classification of French Tenses.-

I. Future,

Futur.

II. Present,

PRE'SENT.

III. Past.

I.-aorist,

2.-progressive,

PASSE' DE'FINI.

IMPARFAIT, 
WORDS BELONGING TO THE CATEGORIES OF TIME. IOI

Classification of English and German Tenses.

I. Present,

Present.

II. Past,

IMPERFECT (the so-called).

Preterit or past are better names for the latter tense.

Analysis of the English Verbs and the verbal properties of the participials.

A.-As event-sign,

I. *of existence (substantive verb),

II. of motion proper,

I.-state,

a) potential (potential verbs),

b) actual,

c) perfect (perfect passive part.)

2.- duration,

a) aorist,

b) progressive (participle in ing),

B.-Predication-power of uniting with a subject.

I. voice,

I.-active,

2.-passive (passive participle only),

II. person,

III. number,

I.-first (fragmentary),

2.- second (fragmentary),

3.- third (fragmentary),

I.--singular,

2.-plural.

C. Assertion,

I. mode,

I.-indicative,

2.- subjunctive,

3.-imperative,

II. tense-time,

I.-present,
2.-past.

*Subdivisions 1 and 2 under II belong to both I and II, 
Classification of words belonging to Time-presentations.

I.-Verbs,

I.-substantive verbs, are, become,

2.- motion-verbs,

a) potential verbs, can, will,

b) transitive,

c) intransitive.

II.-Adverbs,

1.--special,

2.- general,

a) demonstrative,

b) relative,

c) interrogative.

III.-Conjunctions,

I.-co-ordinating,

2.--subordinating.

\section{CHAPTER XVII.}

Words Belonging to Both the Categories of Space and the Categories of Time.

The characteristics of participials.-Nowhere is the ordinary grammar less satisfactory than in its treatment of participles and infinitives. First, we are told that the verb is a word which asserts; and then participles and infinitives are pressed into the service as verbs, and chained in gangs of two and three to the oars, that the classic triremes of conjugations may be filled in all traditional modes, tenses, and voices. What a pity there was not a middle voice in Latin! If there had been, sure as night follows day, we should have had one in English too, and the youth of the land would have been nurtured on stuff like this: I wash myself, thou washest thyself, he washes himself, etc., ad libitum. Participles and infinitives have been pressed into service as verbs, though they certainly do not assert, and, 
moreover, in spite of the fact that they are used as nouns and adjectives. Thus though grammar starts out with the declaration that they are verbs, this is soon forgotten and they are treated as something else. So the participles are the pariahs among words. And perhaps this is caused by the fact that they are the hybrids of language, true participles being hybrids between adjectives and verbs, infinitives being hybrids between substantives and verbs. "His example warning a world." Here, warning is an adjective in relation to example, and a verb in relation to world, the latter word being its direct object. That is, warning is the sign of a quality-presentation in relation to example and of a motion-presentation in relation to world. The art of thus changing the symbol from one category to another, belongs to an advanced stage of thought, and therefore, except in a few stereotyped expressions, we seldom hear participles used by uncultured persons. We shall use the term participials to denote with a common name participles, infinitives, gerunds, gerundives, and supines, in short, all the nominal forms of the verb. These hybrids are of two kinds.

I.-Substantive Participials.

2.-Adjective Participials.

Substantive participials we consider a separate part of speech, belonging both to the category of thing and to that of event. To all the superordinate elements of the sentence, it stands in the relation of a substantive; to all elements subordinate to itself, it stands in the relation of a verb. To its co-ordinate element (subject or predicate) it may stand in either relation. Ex. "He desired to confuse, not to persuade." The infinitives confuse and persuade are direct objects of the verb desired, and hence are in relation to that verb (its subordinate element) substantives. Ex. "To comfort those that were without a comforter, was his mission." The infinitive comfort is subject of the verb was, and hence a substantive in relation to its co-ordinate element; but it is itself determined by the direct object those, and is therefore a verb in relation to its subordinate element. Ex. "He heard Jenny Lind sing." The infinitive sing is here the predicate of Fenny Lind. (To be a predicate it need not 
assert, as it does not do here.) Hence this is an example of an infinitive in the relation of a verb to its co-ordinate element.

The substantive participials in English are the infinitive, the perfect participle after have, and the participle in -ing when used as a substantive but retaining its participial nature. That that which is had, must be thought as a thing, ought to be plain to everybody. "I have loved," means, I possess the action of love as a result. "He has eaten," means, he possesses eating as a completed action. That the "participles" loved and eaten are not adjective participials in these cases (after have), is easily proved by going to a language that declines its adjectives even after verbs. French: $\mathcal{F}^{\prime} a i$ aime', and Nous avons aime', or 'F'eus aime', and Nous ềmes aime'. Whether the subject is singular or plural, the form of aime' is the same, showing that it is not an adjective in nature. The same holds true in the Swedish. And the Swedish grammarians recognize the difference and call the participial after have, not a participle, but a supine. When the passive participle is used in other combinations, it is an adjective participial, as in, "I am loved." Thus, French: Fe suis aime', and vous etes aime'. Here we notice that the participial changes form, as an adjective should.

The participle in -ing is a substantive participial in constructions like these: "Seeing is believing ;" "By ordering up his infantry, the general," etc. The same forms are, plainly, pure nouns when qualified by adjectives, as "Good breeding can not be simulated." There is a singular nonobservance of a grammatical principle in the English idiom which requires the subject of a participle to be in the genitive case. "The news of my going to Paris excited great interest," (from a school-grammar). "His embracing the Christian religion was used as a pretext," etc. The universal principle is that subject and predicate unite on equal terms and are of equal importance; but the genitive case always denotes dependence, subordination. This is one instance among many, showing that the unconscious logic of language is not absolutely infallible. The Greek language permits also a violation of the principle of partici- 
pials. The universal principle is that the elements subordinate to a participial are those of the verb; $i . e$. adverbs, not adjectives, are used to determine participials. But the Greeks used the definite article, which is an adjective, to

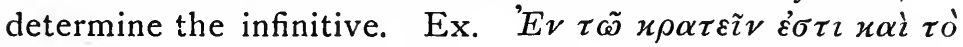

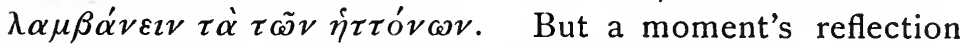
will show that the Greek language violates the letter in order to obey the spirit of language. The article has here no adjective force at all but rather that of a case-ending or preposition. The article is really used to show in what case the infinitive is used. The infinitive being indeclinable, some means must be invented to denote its relations. Articles would never have been used before infinitives by the Greeks, if, like the Latins, they had possessed a declined substantive participial. Besides, the Greek language has a supreme contempt for the rules of mere formal logic, and often violates these in order to satisfy the deeper instincts of thought. For example, the double negative, the singular verb with a plural neuter subject, and the nominative with the infinitive.

The adjective participials might also have been called simply participles, but for the sake of symmetry we shall retain the longer term, though still taking the liberty of using the shorter when we see fit. English has two participles,

a) The perfect passive participle. This participial form is always an adjective participial, except when used as the object of have, when it is here called a supine.

b) The actual active progressive participle. This is the participle in-ing. It is not present; no participials denote time; "a whistling bird," may refer to one that whistled today or whistled a thousand years ago. But the participle can denote state, and the state denoted here is the actual; the act denoted by the participle was at the time of the proposition actualizing itself. It is active, because it represents its subjects as having the relation of agent. And, finally, it is progressive, since it denotes the act as something going on for some time. As the verbs are all active and aorist, no active aorist participle is supplied by the English, 
which avoids nothing so carefully as a superfluity of grammatical forms. The progressive nature of this participle, though always present, is not emphasized except in certain constructions.

Classification of the English Participials.

I.--substantive participials,

a) supines, he has ruled,

b) gerunds, by suffering ills, he etc.,

c) infinitives.

2.--adjective participials,

a) perfect passive participles,

b) actual active progressive participles.

Ordinarily, in referring to the participles, we shall call them the passive and the active participles.

Classification of the Latin hybrid words.

I.- substantive participials,

a) supines,

b) gerunds,

c) actual infinitives, amare,

d) perfect infinitives, amavisse.

2.--adjective participials,

a) perfect passive participles,

b) actual active participles,

c) potential passive participles, or gerundives.

Analysis of Participials.

A. Verbal properties,

I. event-(or duration)sign,

$$
\begin{aligned}
& \left\{\begin{array}{l}
\text { 1.-as existence, being, becoming, } \\
\text { 2.-as motion proper, }
\end{array}\right\} * \\
& \text { a) state, } \\
& a a) \text { potential, futurus, or } \\
& b b) \text { actual, ruling, or } \\
& c c) \text { perfect, ruled, } \\
& \text { b) duration, } \\
& a a) \text { aorist, or } \\
& b b) \text { progressive, }
\end{aligned}
$$

"Subdivisions (a) and (b) (state and duration) under "verbal properties" belong to both (1) and (2). 
II. predication power,

$$
\text { I.-voice, }
$$

B. Adjective properties (of adjective participials),

I. gender,

II. number,

III. case,

C. Substantive properties (of substantive participials),

I. case.

Classes of Words or Parts of Speech.

A. Words belonging to space,

I. Substantives,

I.- - nouns or special substantives,

2.- pronouns or general substantives.

II. Adjectives,

I.-special,

2.- general, or pronominal.

III. Prepositions.

B. Words belonging to time.

IV. Verbs,

I.- substantive verbs,

2.-common.

V. Adverbs,

1.-special,

2.- general.

VI. Conjunctions.

C. Words belonging to both time and space (English).

VII. Substantive Participials,

I.--supines,

2.--gerunds,

3.--infinitives.

VIII. Adjective Participials,

I.-passive participles,

2.- active participles. 


\section{PART V.}

\section{SyntAX.}

\section{CHAPTER XVIII.}

\section{Analysis of Verbal Phrases.}

A systematic treatise of syntax is found in conjunction with dynamics in Part III. We have already explained why this arrangernent seemed preferable to deferring the discussion of syntax to its proper part. But we have a very important portion of the science of sentence-construction left, which could not be discussed before morphology was settled. This portion consists of the so-called "compound verbs," or "verb phrases."

Every sentence expresses an event, and events, as we have seen, differ in temporal properties, as to tense-time, state, duration. A portion of this wealth of time-determinations is expressed by the verb itself, and has accordingly been considered under morphology. The rest is expressed by combinations of words, and belongs to syntax.

The syntax of the "primary symbol" symbol of English has never any future to account for. The verbs may, can, must, need, shall, and will do not express future actions, like the Latin and Greek future tenses. They express a present potentiality. Thus, in $I$ must go, must expresses an actual condition of the subject. The subject's present existence is now such that going will result. In $I$ shall go, neither the verb shall nor the combination shall go raises as the primary symbol a presentation of a future

\footnotetext{
"For meaning of the term "primary symbol" see Teleologic economy.
} 
action. Shall go $=$ a present necessity for going (at some time).

The primary symbol of English thought has, therefore, only two tense-times, present and past. The tense-times are expressed by the verb directly. The perfect event (event as a result) is expressed by have with a perfect participle as its direct object. No doubt the possession expressed by have is actual, but the event expressed by the perfect participle is perfect (a result). Hence the two together assert primarily a "perfect" event.

All English verbs are aorist (that is, unlimited as to duration), but, by asserting existence by the verb is (to be) and adding as an attribute a progressive participle, we can assert as primary symbol a progressive existence. Ex. The roses are blooming.

No English verb is passive, but by the aid of a substantive verb ("to be," \&c.) determined by the perfect passive participle as its attribute, we assert events as passive in relation to the subject.

Kinds of primary event-symbols in English--(The active only are given.)

I. Present,

I.-actual,

a) aorist, sees.

b) progressive, is seeing.

2.-perfect,

a) aorist, has seen.

b) progressive, has been seeing.

3.- potential,

a) aorist, will see.

II. Past,

b) progressive, will be seeing.

I.-actual,

a) aorist, saw.

b) progressive, was seeing.

2.- perfect,

a) aorist, had seen.

b) progressive, had been seeing.

3.-potential,

a) aorist, would see.

b) progressive, would be seeing. 
Kinds of primary event-symbols in the Spanish. (Active.) I. Future,

I.--actual, aorist ("futuro"), hablara.

2.-perfect, aorist ("futuro anterior"), habra hablado.

II. Present,

I.--actual, aorist ("presente"), habla.

III. Past,

2.--perfect, aorist ("perfecte"), ha hablado.

I.- actual,

a) aorist ("preterito perfecto definido"), hablo.

b) progressive ("imperfecto"), hablaba. 2.- - perfect,

a) aorist ("preterito anterior"), hubo hablado.

b) progressive ("pluscuam perfecto") habia hablado.

The French has the same scheme. Only symbols expressible with combinations of verbs and participials are here noted; with the aid of adverbs and other circumlocutions an almost interminable number of shades of temporal and predicative differences can be expressed.

The secondary symbol is the symbol by which the listener to speech chooses to symbolize the thought after he has comprehended the symbol constructed by the speaker. It is often not the same as the primary symbol. When the primary is very artificial or involved, a simpler symbol is generally substituted as secondary. These, naturally, vary with each individual, but as different minds still follow in the main the same course in thinking, these symbols could be at least approximately systematized. If written out, these symbols would form a table somewhat approximating what is now called "conjugation" of the verb. This table would be of little use, however, except in comparing the wealth of expression of one language with another. 


\section{PART VI.}

\section{Application.}

\section{CHAPTER XIX.}

\section{A System of Diagrams.}

To save the reader time and trouble in following our analysis, the following system of diagrams should be used to show the relation of words in the sentence:

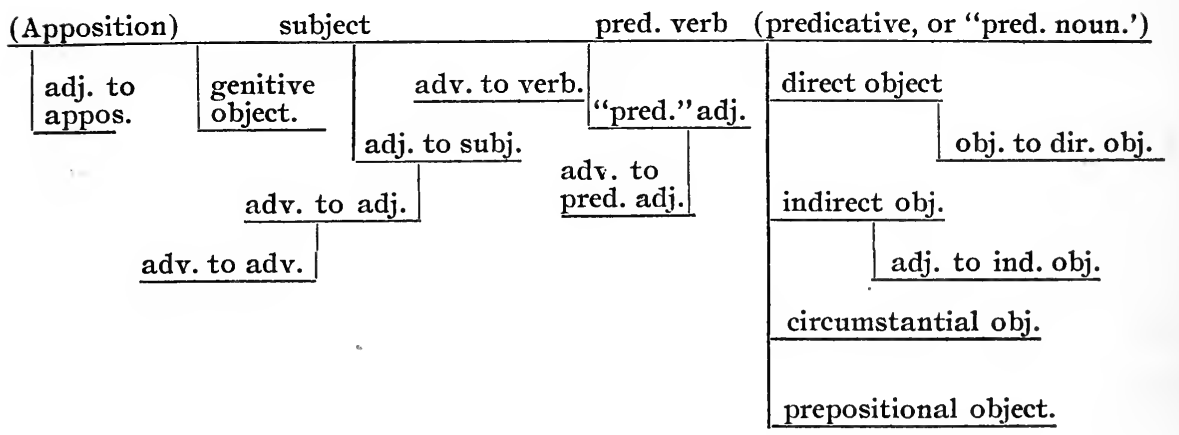

If no direct or indirect object is found, two "rudimentary" lines are left to indicate this, and thus show the rank of the objects found, thus ; " $\mathrm{He}$ is worth a million."
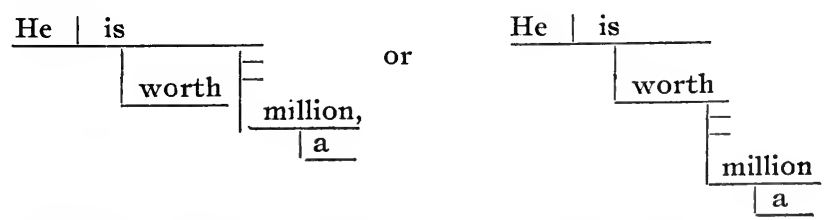

(Either of these analyses can be defended.) 
Adjectives are joined to the right of a perpendicular line, under the middle of the word limited ("modified"). Adverbs are joined to the left of the same line. "Motionobjects" (all except genitives and prepositional objects "modifying" nouns), are joined to perpendicular line near the right extremity of the word determined. Objects of nouns are joined to a line near the left extremity.

Propositions related as propositions are connected with dotted lines; co-ordinate propositions occupy the same level, subordinate propositions are placed below the element determined (modified).

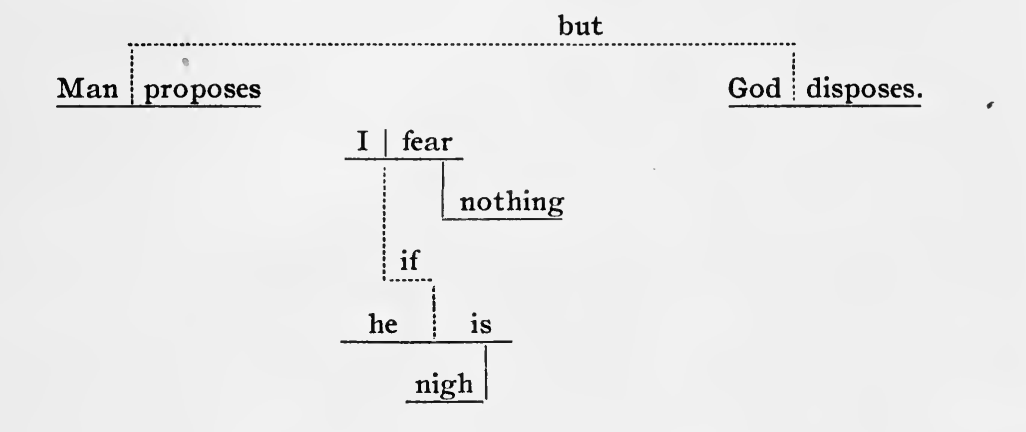

but

Relatives.

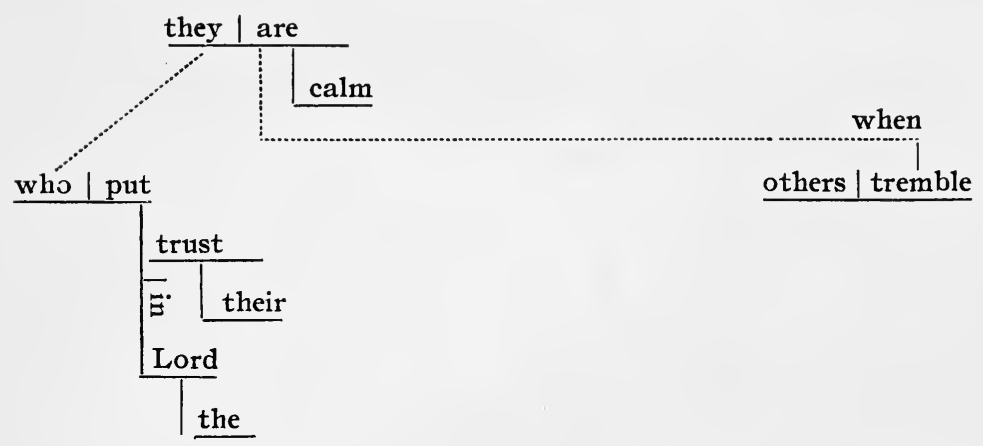

Relatives, when determining a word in the dependent clause also, are put above the determined word in the dependent clause, whenever that is necessary to obviate trouble in connection. 
To simplify diagramming, relative adjectives, when the substantives to which they refer are not expressed, are allowed to take the places of said substantives.

\section{CHAPTER XX.}

\section{Analysis of Disputed Constructions.}

We shall now turn our attention to disputed constructions. First to be considered are the so-called compound tenses of the verb.

The "passive voice." -
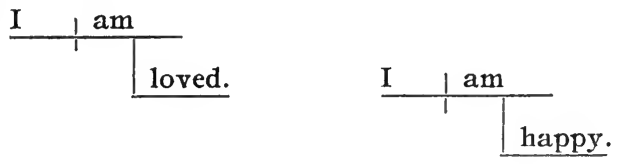

The syntax of these two sentences is the same. Am is in both the predicate, and loved in the one and happy in the other are attributes qualifying the substantive verb am. There is nothing passive about the verb; it is in the indicative present, and can not be said to be either active or passive, since it represents being. Loved being an adjective participial, indicates the word modified as its subject. This is $a m$, but the being in $a m$ is the same as that of $I$, hence it is implied that the subject of loved is I. Loved is truly passive, as it represents its implied subject as passive.

The "perfect tenses."-
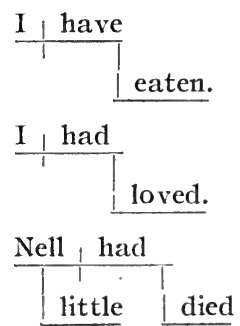
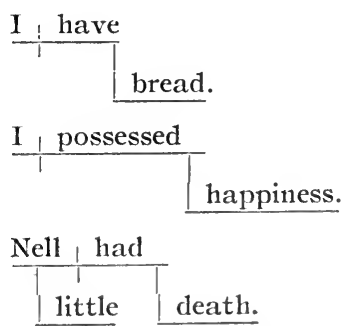

The direct objects of the verbs are eaten, bread, loved, happiness, died, death, alternately substantives and substantive participials. The similarity is apparent. We claim that the 
perfect participle after have is always the direct object of have. Assuredly there is nothing unwarranted in this assumption. Have is certainly a transitive verb, and not only may take an object, but requires one. Substantive participials are often used as direct objects, as all grammars teach. That the participial after have is a substantive participial is apparent. In languages that inflect the adjective participials even after verbs, the participial after have always remains uninflected, as in Spanish, French, and Swedish. In modern Greek, the participials that follow have $\left(\varepsilon^{\prime \prime} \chi \omega\right)$ to form the so-called perfect tenses is the infinitive, which indisputably is a substantive participial. In the popular language, a form derived from the participial is also used, but this is uninflected and ends in $\alpha$, as $T o^{\prime} \nu \varepsilon^{\prime} \chi \omega i \delta \omega \mu \varepsilon \dot{v} \alpha$, I have seen him.

The constructions denominated perfect tenses have developed from expressions of this kind. "The tiger which I keep (have) imprisoned." "He has a written letter." "He has the letter written." "The letter he has (keeps) written."

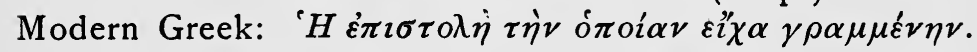
"The king has a prisoner chained to the wall." It will be noticed in these examples, that in every case the participial qualifies the object of have, as an adjective, and is accordingly an adjective participial. But on one great day in the history of modern tongues, the genius of language metamorphosed the whole construction into a new creature. The center of gravity of the old construction lay in the substantive used as object, the participial was but a determination. "The king had the prisoner chained." What sort of a prisoner? A chained prisoner. After the metamorphosis, the center of gravity rests with the participial. Below are diagrams of the two constructions.

The king has the prisoner chained, and, The king has chained the prisoner.
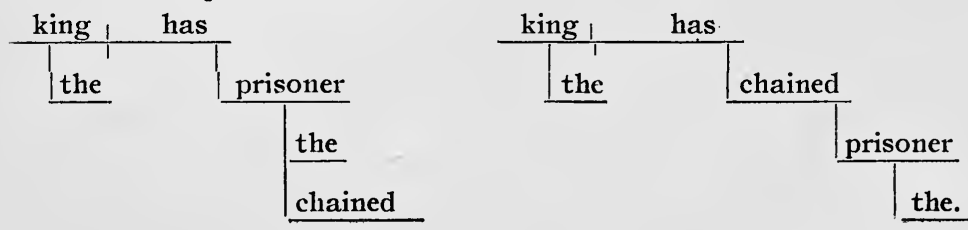
The "future tenses" and the "potential mode."-
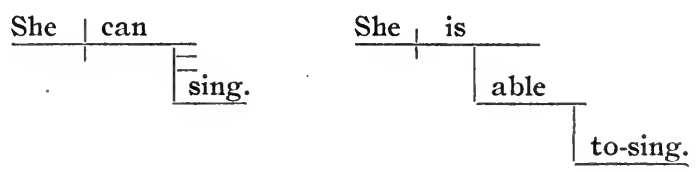

The relation between can and sing is one on which English grammarians are as silent as if it were the esoteric doctrine of a sacred mystery; but the amusing feature about it is, that generally it has been taken for granted that can and sing are but one word. And then, when in a general way the fact that a pair makes two is recognized, the true verb, the most important word of the sentence, is called an auxiliary.

In the first example, subject, she; predicate-verb, can; circumstantial object, the infinitive sing. The second sentence is very similar and shows the correctness of the former analysis. Subj., she; pred., is; attribute of predicate, able; circumstantial object of able, the infinitive, to sing. To is here no proper word; it is only the sign of the infinitive, and may consequently be considered as a part of the infinitive, thus, to-sing. In the last sentence it is an open question whether or not the infinitive to sing ought to be considered as a circumstantial object of the verb is, instead of its subordinate element able. In this case, however, we follow tradition, and this the more calmly, as it seems to us that in the present instance it is not the meaning of the verb at all, but the sense of the adjective able that is determined.

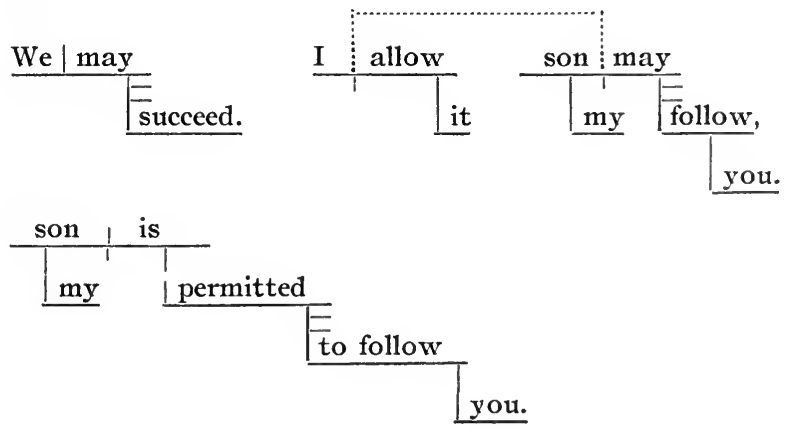


It will be noticed that the verb may has several meanings. In the first example may means subjective possibility; as far as the speaker knew the conditions of the real world, there was no insurmountable obstacle; but in the second problem, may denotes permission, a part of objective potentiality.

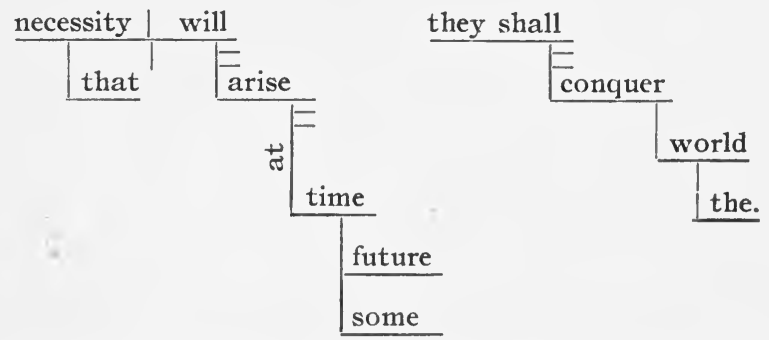

In neither of these cases do we primarily assert a further action. For, to be exact, we assert and predicate no action at all, but a potentiality, that is, a state. The potentiality, moreover, is present in tense. It is now that the necessity will and they shall. Such is their present condition that the action (arise, conquer) is sure to come. As has been shown before, all present tenses in English are also futures. The potentiality is by no means limited to the present time only. But the action that as an object limits the potentiality can, by the very nature of the case, not very well be anything except future action, though nothing in the form of the infinitive does so indicate. "They shall conquer the world," means they possess a present potentiality which must result in the conquest of the world; or, they are in a state from which conquest of the world follows.

Where, indeed, is the future of the future tense? Which of the two following is more future? " $\mathrm{He}$ will strike, $\mathrm{He}$ must strike."

We shall now attack some of the more complex phrases, though their solution follows from what has been already given.

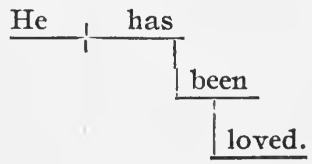


That is, he possesses a being that has the attribute of being loved. But, it might be objected, that this being might be, say, his wife's not his own being. So it might, if been were a substantive, but being a participial it must have a subject; the implied subject of been is, as is usual with participials, the subject of the sentence. It is accordingly expressed that the being in question is the subject's own, and it might be paraphrased thus: he possesses his own being as qualified by the result of love.
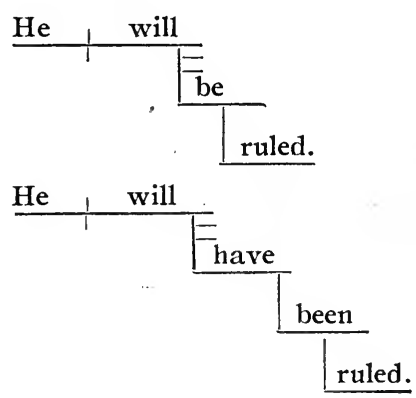

Subj., he; pred., will; circumstantial object of will, have been ruled; direct object of have, been ruled; attribute of been, ruled.

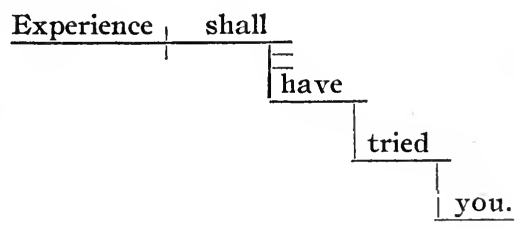

Circumstantial object of shall, have tried you; direct ob. ject of have, tried you; direct object of tried, you.

Some German "compound verbs," which differ from the English, may be profitably considered.
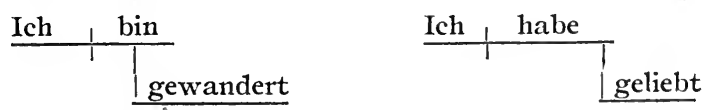

The two constructions are not identical. Gewandert is a perfect participle, that is, an adjective participial and limits bin as an attribute; geliebt is here a supine, hence a 
substantive participial, and limits habe as a direct object.

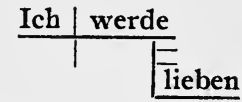

$\frac{\text { Ich } \mid \text { werde }}{1}$
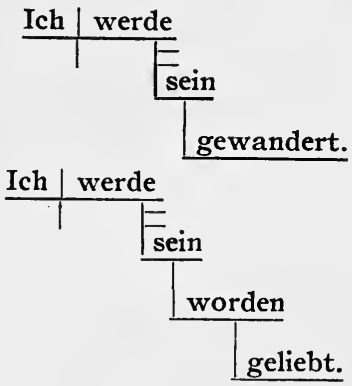

These represent the true grammatical relations. In the last sentence, for example, sein is related only to werde and worden, and to the one as a determination, but to the other as a word to be determined.

Latin has also a few compound tenses explained as follows.
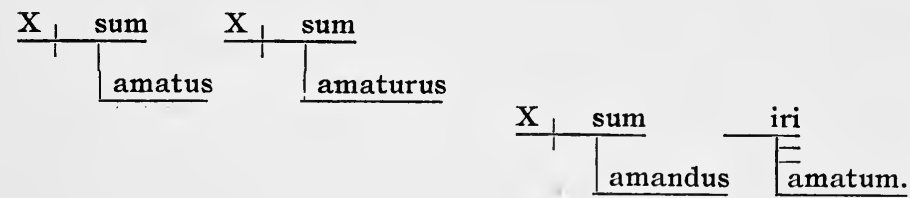

In the three sentences above the existence of ego is asserted. This is limited in the first by qualifying it by the attribute of an action existing as result. The participle is passive and expresses that its implied subject (ego) is joined to it passively. Amaturus qualifies sum by the attribute of an action existing as a potentiality, which is also the case with amandus. The difference is, that one is active, the other passive.

Modern Greek represents many peculiarities, as it uses real modal and temporal particles instead of auxiliaries.

I shall loose, $9 \dot{\alpha}^{\prime} \lambda v^{\prime} \omega$, or $9 \varepsilon^{\prime} \lambda \omega \lambda v^{\prime} \varepsilon$. $\Lambda v^{\prime} \varepsilon \imath$ is here an infinitive.
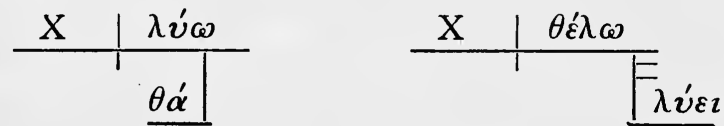
I may loose, $N \alpha_{-} \lambda v^{v} \omega$.

$\frac{\mathrm{X}, \lambda \boldsymbol{v}^{\prime} \omega}{\nu \dot{\alpha} \mid}$

$N \dot{\alpha}$ may also be considered a conjunction. But the "perfect," I have loosed, $\varepsilon^{\prime} \chi \omega \lambda \dot{v} \sigma \varepsilon \varepsilon$.

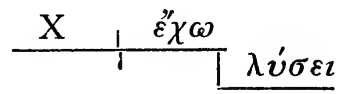

The same construction is found in the last example as in English, though an infinitive takes the place of the English supine. 


\title{
PART VII.
}

\author{
(CoNCLUSION.)
}

\section{CHAPTER XXI.}

Summary.

The fundamental thought of this thesis is that grammar is not only a science but also a branch of philosophy. Every case-ending, every mode and tense, the rules of syntax and their seeming exceptions can be traced back ultimately to the laws of the human mind. The laws on which speech finally depends are the laws of perception and imagination, and only mediately the laws of the concept and judgment. The same inflexible laws of time and space which govern the phenomena of perception, also govern the forms and rules of speech. Here on the very threshold of our investigation we encounter an arch heresy. Attempts have been made to apply the laws of logic to speech. Many logicians do not even stop to notice whether the problems they investigate are verbal or conceptual. This confusion of language and logic, favored as it is by the very etymology of the word logic, has vitiated the principles of both. For a greater mistake can not be made in grammar, than to assume that the laws of the concept apply directly to language. Having established this fundamental principle, that the laws of grammar are based on the nature of the world of presentations, we have attempted to show in detail the unbroken connection with the fundamental principle into the 
uttermost ramifications of inflections and syntax. The results of the inquiry into the fundamental logical and psychological laws of language, is embodied in the nomenclature adopted. Every term implies a theory. For the trained mind, the use of terms like "category of time," "determination by location," and "thing-presentation," ought to be sufficient to indicate the way back to psychological headquarters from the utmost outposts of grammatical exceptions. Our subject possesses a grand philosophical unity and continuity which knows of no hiatus from the beginning of psychology to the end of grammar, and it has been our aim to indicate this unity as fully as possible.

At the very foundation of our system lies the distinction between symbol and meaning. We agree here to a certain extent with the English logicians, F. H. Bradley and B. Bosanquet. Their doctrines of symbol and meaning, though all that is necessary for their purposes, are not quite sufficient for our investigations. Symbols belong to the world of time and space only, meaning to the realm of concepts. The world of time and space includes memory, imagination and perception. Its contents are presentations. There is no difference between presentations, so far as the laws of time and space, and, consequently, the laws of symbolism, are concerned. The symbol is never the meaning; the meaning (or concept) is never known except in and through a symbol. This is a pair of most vital principles. Several thinkers of note seem, however, to hold views somewhat conflicting with this. Wm. Wallace, in the Preface to his translation of Hegel's Logic, seems to oppose pictorial thought to pure thought. The same is noticed in the writings of Dr. W. T. Harris. How far these acute thinkers wish to be construed in a manner that first suggests itself to the ordinary reader, is hard to determine. We still hope that they hold with us that "pure thought" consists in a clear consciousness of the mere symbolic value of images in thought, and not in a process of thinking that is emancipated from all temporal and spatial symbols. The other principle, that the symbol is never the meaning, seems to be contradicted by F. H. Bradley, as has been noticed before.* Other ex-

* See page 9, Principles of Logic. 
pressions of his seem to agree with our view. It is only fair to state, that to all these thinkers the question of the relation of symbol and meaning is only of secondary importance, and is hence treated rather incidentally.

In Part Second, the laws of the presentation-world in reference to symbolism, and their connection with the classes and properties of words, are investigated. Here we move in the realm of images and percepts, but must take notice of the laws of the conceptual world in so far as these laws affect the use of images and percepts as symbols.

The doctrine of the inclusiveness of time and the exclusiveness of space is a principle of great importance, not only in the symbolism of language, but in all departments of philosophy. A misunderstanding must be guarded against. By saying that time is the form of continuity, or unity, it is not affirmed that time itself may not be conceived as a succession of discreet moments; and by asserting that space is the form of particularity, plurality, it is not said that space itself may not be thought as a continuum. What is affirmed concerns the contents of time and space. We can not help thinking that the contents of time to-day are the same as of yesterday. The world may look different but "in reality" it is the same, we say. The laws of the conservation of energy and the indestructibility of matter are simply explicit statements of this fundamental character of time. Sir Wm. Hamilton's law of the condition, Kant's causality, and Hegel's second stage of thought are all more or less happy attempts to express this principle of time in relation to the human mind. But on the contrary, it is also impossible to believe that two portions of space, however minute and however close together, can contain the same particle of matter. This is what is meant by the exclusiveness of space. How beautifully this explains the facts of grammar, is easily shown when it appears that number and case can be deduced directly from the exclusion of space in the category of things; and when it is shown that the "state" and "duration" of the verb come directly from the inclusiveness of time as this appears in the category of motion. 
There is a beautiful symmetry and correspondence between the two sets of categories. Thing and event, quality and manner, position and succession, are at once the counterparts and complements of each other. The first categories of time and space are the simplest, most natural and direct. The last pair is more artificial, being an application of the laws of the opposite fundamental form, just as the laws of space applied to time by the category of succession.

From a practical point of view, the most important results in Parts II-IV are found in the treatment of the verb. Two new properties are discovered, state and duration; the pure time distinctions are reduced to three, and in the case of the English to two, past and present; participles and infinitives are separated from verbs and established as new classes co-ordinate with the other parts of speech; predication and assertion are distinguished, and true tense and mode referred to the latter; all the properties of the verb are referred to the fundamental properties of assertion, predication, and representation of events. Other "practical" results are the dis-establishment of the article as a separate part of speech ; the classing together of nouns and pronouns as a new part of speech, substantives; and the revolutionized doctrine of cases as treated from the standpoint of the category of position. The treatment of participials is also of a radical character. Attempts have been made to show how all these results are reached by a strict application of the fundamental principles previously established.

Grammar as usually taught confuses verbal predication and logical judgment. This is an unavoidable error so long as symbol and meaning are not differentiated. Predication has to do with the symbol, and consists in signifying by words the joining of an event-presentation with a presentation of thing. Assertion is the appearance of the logical judgment in the sphere of language. These subjects are treated at the beginning of Part Third (Chapters IX and $\mathrm{X})$. While the ordinary school logics disagree with us, we are happy to state that, as far as they go into the question, 
we can claim kinship in these doctrines with men like $F$. $H$. Bradley and B. Bosanquet.

Of special importance is the treatment of the substantive verb. This has a certain kinship with the substantive, because of the fact that its category (existence) can also be used as a higher expression of the category of substantives (things). Therefore we claim that the substantive used after the substantive verb is in the relation of an appositive to the verb. The term predicative has been invented to express this element. The adjective that occurs in the predicate with substantive verbs is an attribute of the verb in the same manner as other adjectives are attributes of substantive::

The treatment of objects in syntax should be noticed as an example of how directly and decisively the laws of the categories decide the principles of syntax. That all participles must have subjects; the distinction between a predict and a proposition; the principles that inside the proposition there is no time, that words determine according to spatial laws and propositions according to temporal laws, are some of the more important results that differ from accepted syntax.

The guiding conception in this thesis is that grammar, in order to be a science, must be based on a philosophy. This is decidedly out of the trend of nineteenth century thought, but we may venture the prediction that it will not be so far from the main channel of thinking in the twentieth century. The thought of to-day is dazzled by the success of the evolutionary treatment of biology; and history of development is the alpha and omega of wisdom to the thinkers that follow the fashion of the hour. Many a wily philosopher has, accordingly, simply coated his potent pills of thought with a thin shell of history, as he knew this to be the only way to make the learned mob notice his theories. Thus, we get historical schools in political science, historical phonetics in philology, history of philosophy in place of philosophy, and have even come so far as to hold that an examination of the manner in which, historically, conceptions of right conduct enter human thought is the sum-total of ethics! 
Be it far from us to deny that the enthusiasm for historical study has thrown an invaluable light on every department of knowledge; but still, it is the duty of the independent thinker to recognize the limitations of every method, and to be fettered by none. Historical philology has accomplished much, and more may be in store for it in the future; but it never will discover any substitute for the philosophical foundations of the science of language; for these foundations are not phenomena of history, they are above and beyond history, they are the logical and psychological laws of consciousness itself. 




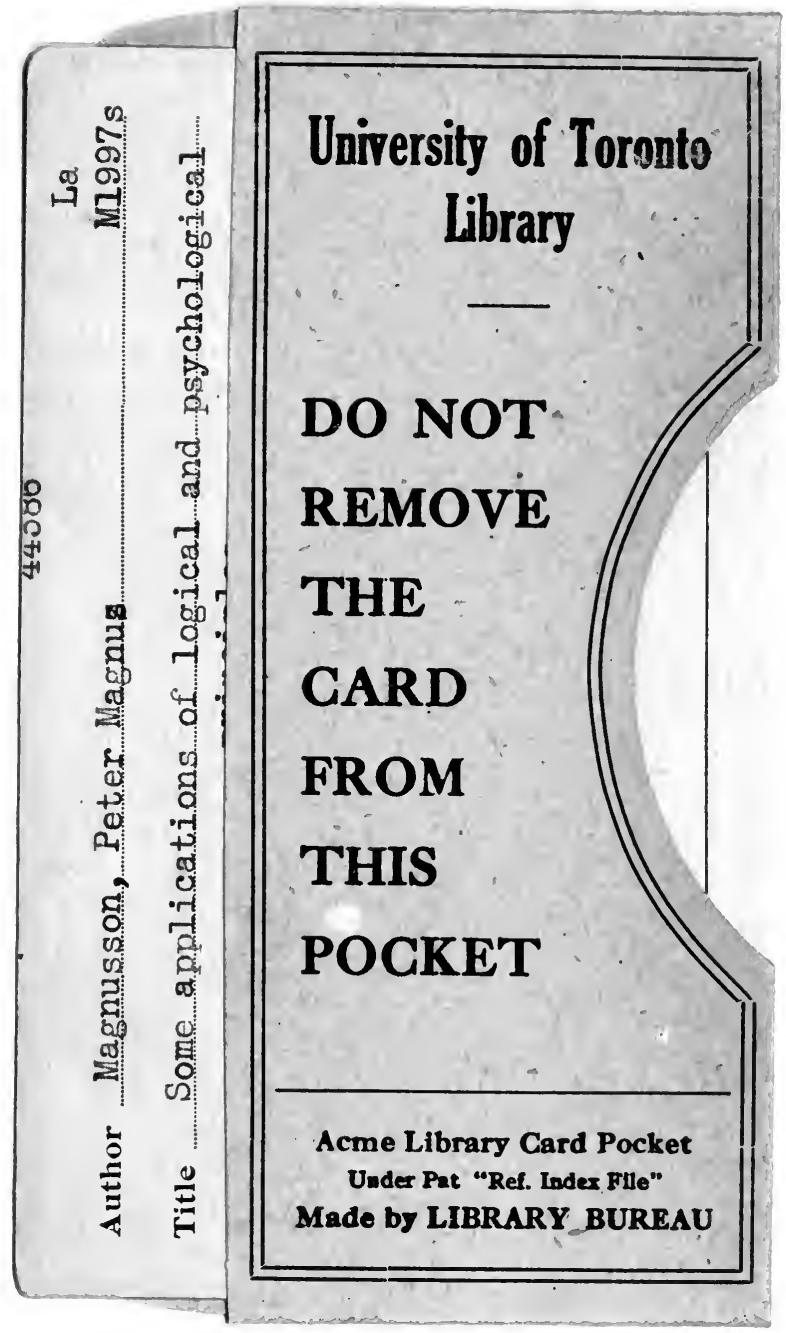




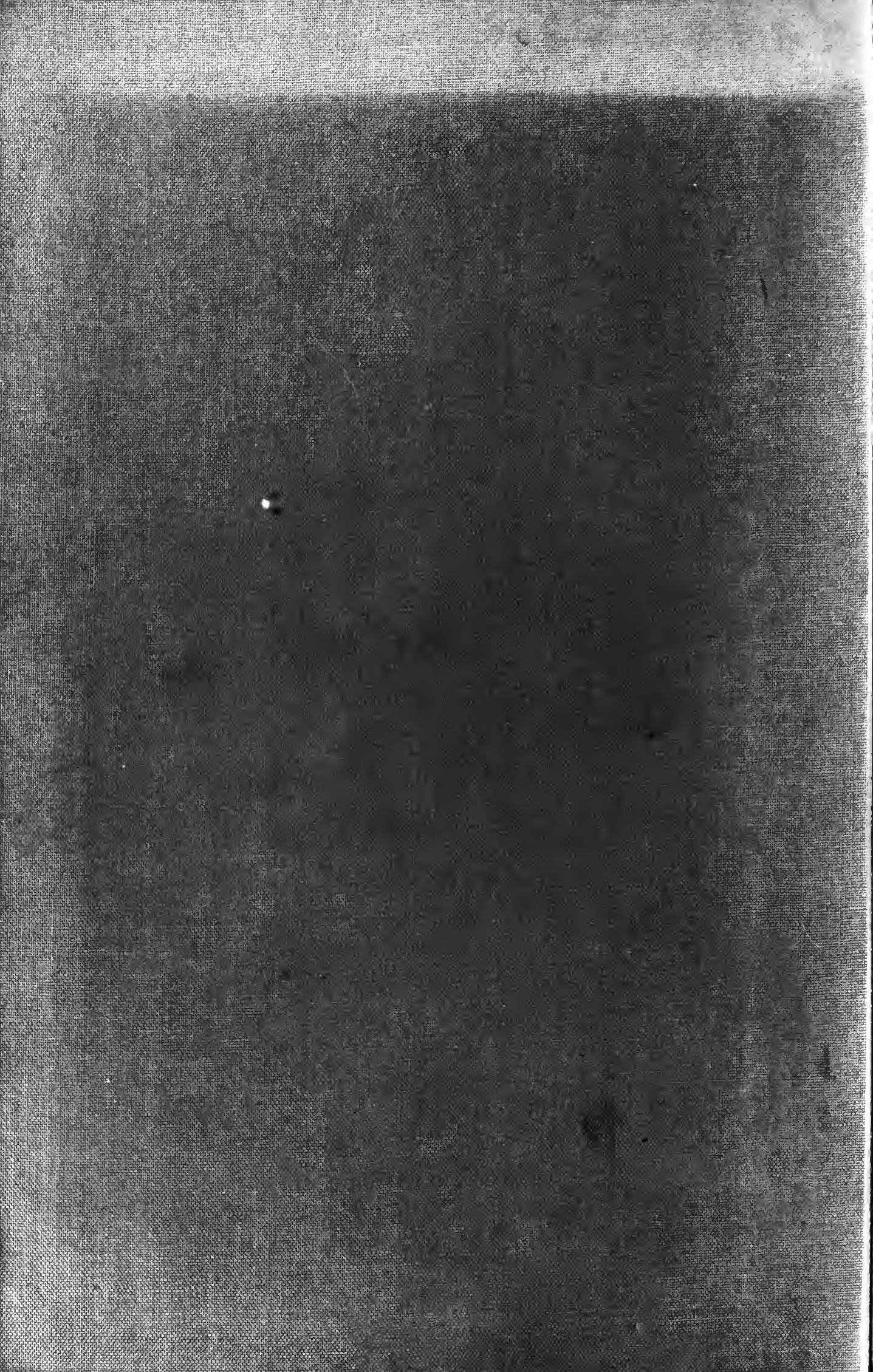

